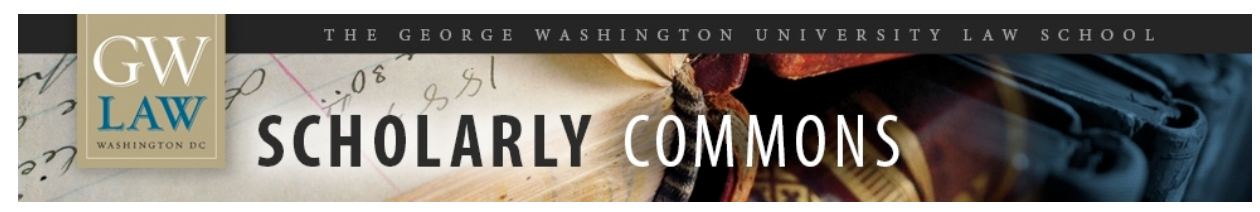

GW Law Faculty Publications \& Other Works

Faculty Scholarship

2014

\title{
A Holistic Look at Agency Enforcement
}

Robert L. Glicksman

George Washington University Law School, rglicksman@law.gwu.edu

David L. Markell

Follow this and additional works at: https://scholarship.law.gwu.edu/faculty_publications

Part of the Law Commons

\section{Recommended Citation}

FSU College of Law, Public Law Research Paper No. 677

This Article is brought to you for free and open access by the Faculty Scholarship at Scholarly Commons. It has been accepted for inclusion in GW Law Faculty Publications \& Other Works by an authorized administrator of Scholarly Commons. For more information, please contact spagel@law.gwu.edu. 


\title{
A Holistic Look at Agency Enforcement
}

\author{
David L. Markell* and Robert L. Glicksman ${ }^{*}$
}

\begin{abstract}
The law review literature has long-recognized that effective enforcement is an essential component of effective regulation. Yet much of the literature focuses on one aspect of the enforcement challenge or another. For example, the underlying theory about optimal levels of enforcement has received considerable attention, as have topics such as the relative merits of using deterrence-based versus cooperation-based approaches and the use of citizen suits.
\end{abstract}

The purpose of this article is to fill a gap in the law review literature by considering agencies' enforcement and compliance promotion function holistically. In doing so, the article approaches the challenge from an "inside-out" perspective, a perspective that administrative law scholars have found to be lacking in the literature.

The article proposes a three-layered conceptual framework for considering options for structuring the administrative agency enforcement and compliance promotion function. The first layer consists of five components of effective enforcement and compliance: norm clarity, norm achievability, verifiability, an appropriate mix of sanctions and rewards, and indicia of legitimacy. The second involves the inter-related character of these components and highlights the importance of fitting each into a particular enforcement and compliance regime so that agencies may gain synergistic benefits and consider the need to make difficult trade-offs. Third, and finally, our conceptual framework includes four contextual design issues that create additional challenges in determining the appropriate content of each of the five key components of effective enforcement and compliance: the hybrid character of contemporary governance efforts; the importance of "reality-checking" enforcement options through close attention to past performance as well as future challenges and opportunities; the dynamic character of environmental governance challenges; and the salience of possible design changes and the need to prioritize design improvements. The article suggests that it is important to consider all three layers in developing an effective enforcement and compliance promotion regime.

The article tests our conceptual framework by including a case study of an ongoing Environmental Protection Agency (EPA) effort to reinvent its enforcement and compliance promotion program and by applying our framework to EPA's initiative. This case study illustrates the value of our framework in evaluating regulatory design options for the enforcement and compliance promotion function.

\footnotetext{
* Stephen M. Goldstein Professor of Law, Florida State University College of Law.

** J. B. \& Maurice C. Shapiro Professor of Environmental Law, George Washington University Law School. The authors thank William Andreen, Robin Craig, David Freeman Engstrom, Emily Hammond, Shi-Ling Hsu, J.B. Ruhl, Sidney Shapiro, Hannah Wiseman, and Sam Wiseman for helpful comments on drafts of this article. Thanks also to Katrina Miller, Research Librarian, Florida State University College of Law, and to Sarah Haston, Florida State University College of Law ('15) for terrific assistance. In addition, thanks to the Florida State University College of Law and the George Washington University Law School for support.
} 


\section{Table of Contents}

Introduction

I. Effective Regulation: Key Components and Contextual Design Challenges

A. Five Key Components of Effective Regulation

1. Clarity

2. Achievability

3. Verifiability

4. The Mix of Rewards and Sanctions

5. Legitimacy

B. Inter-Relatedness of the Five Components of Effective Regulation

C. Contextual Design Challenges

1. Hybrid Governance

2. "Reality Check" as a Contextual Design Issue

3. Dynamism

4. Salience

II. Contextualizing the Conceptual Framework for Effective Regulatory Compliance Design: An Overview of EPA's Compliance Track Record and Challenges

A. Agency Enforcement Records

B. Declining Resources

C. Changes in the Regulated Community and Regulator Responsibilities and Capacities: The Dynamic Character of Regulation

D. A Brief Conclusion Concerning the Importance of Context to Regulatory Design III. A Review of EPA's Initiative to "Transform" Compliance and Enforcement under the Clean Water Act
A. The Need to Focus Enforcement on the Most Significant Threats
B. Strengthening the State/EPA Partnership
C. Improving Accountability and Transparency
D. Enhancing Reinvention through Holistic Regulatory Evaluation

IV. Conclusion

\section{$\underline{\text { Introduction }}$}

The law review literature has long-recognized that effective enforcement is an essential component of effective regulation. ${ }^{1}$ Yet much of the literature focuses on one aspect of the enforcement challenge or another. For example, the underlying theory about optimal levels of enforcement has received considerable attention, ${ }^{2}$ as have topics such as the relative merits of using deterrence-based versus cooperation-based approaches and the use of citizen suits. ${ }^{3}$

\footnotetext{
${ }^{1}$ See, e.g., David L. Markell, The Role of Deterrence-Based Enforcement in a "Reinvented" State/Federal Relationship: The Divide Between Theory and Reality, 24 HARV. ENVTL. L. REV. 1, 4 (2000) [hereinafter Markell, Deterrence-Based Enforcement].

${ }^{2}$ See, e.g., Max Minzner, Why Agencies Punish, 53 WM. \& MARY L. REV. 853, 860-61 (2012); Michael Faure, Effectiveness of Environmental Law: What Does the Evidence Tell Us?, 36 WM. \& MARY EnVTL. L. \& POL'Y REV. 293, 320-30 (2012); David A. Dana, The Perverse Incentives of Environmental Audit Immunity, 81 IowA L. REV. 969, 1004-06 (1998); Richard J. Pierce, Small Is Not Beautiful: The Case Against Special Regulatory Treatment of
} 
The purpose of this Article is to fill a gap in the law review literature by considering agencies' enforcement and compliance promotion function holistically. The Article approaches the challenge from an "inside-out" perspective, ${ }^{4}$ a perspective that administrative law scholars have found to be lacking in the academic literature. ${ }^{5}$

Small Firms, 50 ADMIN. L. REV. 537, 563-64 (1986). Each of these sources cites the seminal article on optimal deterrence, Gary S. Becker, Crime and Punishment: An Economic Approach, 76 J. PoL. Econ. 169 (1968).

${ }^{3}$ See, e.g., David Freeman Engstrom, Agencies as Litigation Gatekeepers, 123 YALE L.J. 616 (2013); Robert L. Glicksman \& Dietrich H. Earnhart Depiction of the Regulator-Regulated Entity Relationship in the Chemical Industry: Deterrence-Based v. Cooperative Enforcement, 31 WM. \& MARY ENVTL. L. \& Pol'Y REv. 603 (2007); Matthew C. Stephenson, Public Regulation of Private Enforcement: The Case for Expanding the Role of Administrative Agencies, 91 VA. L. REV. 93 (2005); Barry Boyer \& Errol Meidinger, Privatizing Regulatory Enforcement: A Preliminary Assessment of Citizen Suits Under Federal Environmental Laws, 34 BUFF. L. REV. 833 (1985).

We credit Professor Engstrom's insightful and provocative recent article, which seeks to improve regulatory design in this realm, for motivating this effort. Professor Engstrom focused on the rationalization of private and public enforcement litigation through agency gatekeeping options for private enforcement litigation, both conceptually and in the context of specific agencies such as EPA. While we focus here on EPA, many of our points are generalizable beyond that agency. We obviously bear responsibility for any missteps we may have made in attempting a reformulation and quite different elaboration than Engstrom's of the central challenges of designing an apparatus that is responsive to current challenges facing the modern regulatory state in the enforcement realm. For insightful syntheses of economists', political scientists' and management theorists' perspectives on regulatory design in addressing environmental challenges, see, e.g., Thomas P. Lyon, Environmental Governance: An Economic Perspective, in Governance for the EnVIRonment: New Perspectives 43 (Magali A. Delmas \& Oran R. Young eds., Cambridge Univ. Press 2009) [hereinafter GOVERNANCE FOR THE ENVIRONMENT]; Maria Carmen Lemos \& Arun Agrawal, Environmental Governance and Political Science, in GOVERNANCE FOR THE EnVIRONMENT, supra, at 69; Andrew King \& Michael W. Toffel, Self-Regulatory Institutions for Solving Environmental Problems: Perspectives and Contributions from the Management Literature, in id. at 98. The Canadian Auditor General has used a "plan-do-check-improve" model to evaluate management of Environment Canada's enforcement program. Office of the Auditor General of Canada, Report of the Commissioner of the Environment and Sustainable Development, Enforcing the Canadian Environmental Protection Act, 1999, at 8 (Dec. 2011) [hereinafter Auditor General Report], available at http://www.oag-

bvg.gc.ca/internet/english/parl_cesd_201112_03_e_36031.html.

${ }^{4}$ Sidney A. Shapiro \& Ronald F. Wright, The Future of the Administrative Presidency: Turning Administrative Law Inside-Out, 65 U. MIAMI L. REV. 577, 578, 597-603 (2011) (contrasting "inside-out" accountability, which they describe as "the potential of promoting ... effective government from inside the bureaucracy. .." and note has been a focus of public administration scholars, with administrative law scholarship, which has focused on "outside-in" accountability stemming from the administrative presidency, congressional oversight, and judicial review).

${ }^{5}$ Emily Hammond \& David L. Markell, Administrative Proxies for Judicial Review: Building Legitimacy from the Inside-Out, 37 HARV. ENVTL. L. REV. 313, 319 (2013) (noting the prevalence of "recent calls for bringing an emphasis on inside-out legitimacy"); Shapiro \& Wright, supra note 4, at 578 (noting that "[administrative law scholarship focuses almost exclusively" on controlling agency operations from outside of the agencies, and observing that, "with only a few exceptions ... administrative law scholars treat agencies as a black box to be controlled from the outside, using political oversight and judicial review"). Some legal scholars, of course, have paid close attention to the operation of discrete aspects of agency enforcement regimes. See, e.g., JoEL A. MinTZ, ENFORCEMENT AT THE EPA: High STAKES AND HARD CHOICES (revised edition) (University of Texas Press 2012); Daniel C. Esty, Toward Optimal Environmental Governance, 74 N.Y.U. L. REV. 1495 (1999) (discussing welfaremaximizing strategies to create ideal governance); Robin Kundis Craig, Valuing the Public Health Aspects of Environmental Enforcement: Qualitative versus Quantitative Evaluations of Enforcement Effort, 33 S. ILL. U. L.J. 403 (2009) (urging greater reliance on quantitative metrics to drive agency enforcement choices). The federal Environmental Protection Agency (EPA), among others, has engaged in numerous efforts over the years to develop, revisit, and improve upon agency approaches in the enforcement and compliance arena. See, e.g., James M. Strock, EPA's Environmental Enforcement in the 1990s, 20 ENVTL. L. REP. 10327 (August 1990); EPA, Enforcement FourYear Strategic Plan: Enhanced Environmental Enforcement for the 1990's (Feb. 1991), available at 
The Article begins by proposing a three-layered conceptual framework for considering options for structuring the administrative agency enforcement and compliance promotion function. First, it identifies five components of effective regulation both generally and in the specific context of regulatory enforcement and compliance: norm clarity, norm achievability, verifiability, an appropriate mix of sanctions and rewards, and indicia of legitimacy. ${ }^{6}$ Beyond examining the importance of these components in establishing and implementing enforcement and compliance promotion policies, we consider some of the complexities involved in fitting each component into particular regimes so that agencies may take advantage of opportunities to gain synergistic benefits and consider the need to make difficult trade-offs. This assessment of how each component relates to the others is the second layer in the framework we propose. ${ }^{7}$

The third layer of our framework for evaluating enforcement and compliance promotion functions relates to what we term "contextual design challenges." 8 One contextual design issue

http://yosemite.epa.gov/water/owrccatalog.nsf/9da204a4b4406ef885256ae0007a79c7/fbfb518793cd84c385256b060 0723741! OpenDocument. EPA is in the midst of its latest initiative, which it calls Next Generation Compliance. See infra Part III. Government interlocutors, scholars, and others have also weighed in on the structure of agency enforcement programs and continue to do so. E.g., National Academy of Public Administration, Evaluating Environmental Progress: How EPA and the States Can Improve the Quality of Enforcement and Compliance Information (June 2001); U.S. GAO, Environmental Protection: More Consistency Needed Among EPA Regions in Approach to Enforcement (2000), available at www.gao.gov/new.items/rc00108.pdf; U.S. EPA Office of Inspector General, Consolidated Review of the Air Enforcement and Compliance Assurance Programs III (1997); U.S. EPA Office of Inspector Gen., U.S. GAO, EPA's Effort to Improve and Make More Consistent its Compliance and Enforcement Activities (2006), available at http://www.gao.gov/products/GAO-06-840T.

We have also sought to advance thinking in this arena. See CLIFFORD RECHTSCHAFFEN \& DAVID L. MARKELL, REINVENTING ENVIRONMENTAL ENFORCEMENT AND THE STATE/FEDERAL RELATIONSHIP (2003); Markell, Deterrence-Based Enforcement, supra note 1; David Markell, EPA Enforcement: A Heightened Emphasis on Mitigation Relief, 45 TRENDS 13 (2014); Alejandro E. Camacho \& Robert L. Glicksman, Functional Government in 3-D: A Framework for Evaluating Allocations of Government Authority, 51 HARV. J. ON LEGIS. 19 (2014).

${ }^{6}$ See infra Part IA. As with virtually all categorization efforts, ours is contestable, and alternative characterizations are possible. See, e.g., U.S. EPA, Principles of Environmental Enforcement I-5 (Feb. 1992) (listing as important components of an effective enforcement program factors such as: 1) establishing enforceable requirements; 2) identifying regulated parties; 3) setting priorities; 4) promoting compliance; 5) monitoring compliance; 6) responding to violations; 7) clarifying roles and responsibilities; and 8) evaluating performance) [hereinafter EPA, Environmental Enforcement]; Paul B. Smyth and Milo C. Mason, Making Tough Choices Easier: Compliance and Enforcement 102, 3-SPG NATURAL RESOURCES \& ENV'T 3 (2004); Douglas M. Costle, Environmental Regulation and Regulatory Reform, 57 WASH. L. REV. 409, 423 (1982) (former EPA Administrator listing as characteristics of effective regulation clarity and certainty, reasonableness and fairness, and efficiency and cost-effectiveness); Meredith James, Results-Based Environmental Regulation in Canada: Creative Solution or Re-Branding Regulation?, 19 J. ENVTL. L. \& PRAC. 139, 143 (2009) (identifying effectiveness and efficiency as the usual focus of debates about tool selection and including as characteristics of effective regulation "clear, measurable, enforceable standards and mandatory language"). Cf. Dr. Paul Harpur, New Governance and the Role of Public and Private Monitoring of Labor Conditions: Sweatshops and China Social Compliance for Textile and Apparel Industry, 38 RUTGERS L. REC. 1, 1 (2010-2011) ("Effective regulation has three essential components. First, the law must develop standards; second, there must be sufficient monitoring of compliance to detect non-compliance; and third, there must be some form of motivation to avoid non-compliance.") (citing STEPHEN BREYER, REGULATION AND ITS REFORM 5 (1982)); Report of the Committee on Ethics, 15 ENERGY L.J. 193, 195 (1994) (listing as components of effective ethics regulation moral resonance, clarity of purposes, non-triviality, practicality, equity, and proportionality).

${ }^{7}$ See infra Part 1B.

${ }^{8}$ See infra Part IC. The purpose of identifying these challenges is to provide an organizing structure for comparing the merits of alternative ways to design administrative programs such as enforcement and compliance inducement programs. For alternative conceptualizations, see, e.g., Orly Lobel, The Renew Deal: The Fall of Regulation and the 
relates to the hybrid character of contemporary governance efforts; as the "new governance" and other literatures reflect, ${ }^{9}$ governance is no longer the exclusive province of the government, if it ever was, and those seeking to design effective regulation should consider the multiplicity of actors. ${ }^{10}$ The capacity of each actor to affect compliance is relevant to the desirability of alternative options for the structuring of enforcement and compliance programs. A second challenge is the importance of confronting past performance as well as future challenges and opportunities. Past failures to consider performance of wide swaths of the regulated community, for example, counsel in favor of considering changes to enforcement regimes to account for at least the more significant outliers. ${ }^{11}$ A third design issue stems from the dynamic character of governance challenges. As the regulatory treatment of the environmental issues posed by climate change reflects, normative objectives are likely to be dynamic in some cases. ${ }^{12}$ The nature of the tools available to government and other key stakeholders also may shift because of factors such as technological advances and changes in resource availability. A sharp reduction in government enforcement resources, for example, might suggest the need to facilitate private enforcement. It is essential to consider these dynamic aspects of the regulatory landscape in structuring enforcement and compliance efforts. Finally, the salience of possible design changes, and the need to prioritize design improvements, is a fourth critical contextual design challenge. Resource limitations, for example, limit government enforcement and compliance promotion capacity, requiring policymakers to decide which efforts are the most critical. ${ }^{13}$

The Article also tests our conceptual framework by including a case study of an ongoing Environmental Protection Agency (EPA) effort to reinvent its enforcement and compliance promotion program and by applying our framework to EPA's initiative. ${ }^{14}$ This case study

Rise of Governance in Contemporary Legal Thought, 89 MiNN. L. REV. 342 (2004) (providing a framework for a governance model which includes "increased participation of nonstate actors, stakeholder collaboration, diversity and competition, decentralization and subsidiarity, integration of policy domains, flexibility and noncoerciveness, adaptability and dynamic learning, and legal orchestration among proliferated norm-generating entities").

${ }^{9}$ See, e.g., Lobel, supra note 8, at 466-70 (describing the goals of new governance as "economic efficiency, political legitimacy, and social democracy"); Neil Gunningham, The New Collaborative Environmental Governance: The Localization of Regulation, 36 J. L. \& SoC'Y 145, 146-150 (2009) (discussing the characteristics of new governance in an environmental context).

${ }^{10}$ E.g., Engstrom, supra note 3 (focusing on rationalization of private and public enforcement litigation as part of the effort to improve regulatory design).

${ }^{11}$ EPA is attempting such an assessment in its reinvention effort, as we discuss in more detail in Part III, infra.

12 See, e.g., Robin Kundis Craig \& J.B. Ruhl, Designing Administrative Law for Adaptive Management, 67 VAND. L. REV. 1 (2014); Robin Kundis Craig, "Stationarity is Dead" - Long Live Transformation: Five Principles for Climate Change Adaptation Law, 34 HARV. EnVTL. L. REV. 9, 17, 66-67 (2010) J.B. Ruhl, Climate Change and the Endangered Species Act: Building Bridges to the No-Analog Future, 88 B.U. L. REV. 1, 39-40 (2008).

${ }^{13}$ EPA appears to be at risk of experiencing such reductions. See infra Part II; Sean Reilly, EPA sees reductions in enforcement, inspections through 2018, FEDERALTIMES (Feb. 21, 2014), available at http://www.federaltimes.com/article/20140221/MGMT05/302240003/EPA-sees-reductions-enforcementinspections-through-2018.

${ }^{14}$ See infra Part III. This article offers what we hope is a constructive contribution to the debate about whether legal scholarship is (in)sufficiently tethered to the real world. It attempts to evaluate the real world practicability of our conception of the manner in which the regulatory state operates in light of an agency's actual practices and procedures. For differing views about the value of legal scholarship in terms of the resolution of real-world challenges, see, e.g., Harry T. Edwards, The Growing Disjunction Between Legal Education and the Legal Profession, 91 MiCH. L. REV. 34, 36 (1992) (endorsing scholarship that reflects "a healthy balance of theory and doctrine"); Catherine A. MacKinnon, Engaged Scholarship as Method and Vocation, 22 YALE J.L. \& FEMINISM 193, 
illustrates the potential value of our framework in evaluating regulatory design options for the enforcement and compliance promotion function.

Part I of the Article lays out our conceptual framework. It first identifies and examines why each of the five components of effective regulation we have identified is important in establishing and implementing enforcement and compliance promotion policies. Next, Part I explains why it is important in thinking about the structure and content of an enforcement and compliance program to consider these five components holistically; it is, in our view, of foundational importance to consider how the structure and operation of each of the components influences the others. The third section of Part I introduces the third layer of our multi-layered conceptual framework, which is comprised of four contextual design challenges that we believe may significantly influence how one should approach design and implementation of an effective enforcement and compliance promotion regime.

Part II contextualizes how an agency might begin to consider the design of its enforcement and compliance regime by focusing on one agency's (EPA's) track record. This Part examines two features of past performance that are of particular importance (the adequacy of agency resources and the nature of the regulated community) and the implications of changes in each feature for the future operation of enforcement and compliance programs. This Part helps to ground the paper by offering our perspective on EPA's past enforcement performance and some significant challenges and opportunities the agency faces.

Part III is an initial attempt to give our framework a test run. It provides an overview of an ongoing EPA initiative to re-invent its promotion of compliance with the Clean Water Act (CWA)'s regulatory requirements. In this Part, we consider EPA's ongoing reinvention effort in light of the conceptual framework we have introduced (in Part I) and EPA's track record and anticipated challenges and opportunities (discussed in Part II). In doing so, we explain how the application of our framework would enrich EPA's analysis of available options for restructuring its CWA compliance promotion program. In addition to providing insights on EPA's program, we hope our work fuels analysis of the design and implementation of other regulatory programs and, relatedly, demonstrates how the context in which a particular program operates is likely to affect the manner in which the regulatory components we have identified can contribute to (or detract from) effective regulation. ${ }^{15}$

204 (2010) (urging scholarship that "is both grounded and theoretical, actively involved in the world of its subject matter, and for that reason, able to think about it in fresh ways").

We are most familiar with EPA and hence have focused on regulatory design issues based on that agency's compliance promotion strategies. Regulatory design is likely to be highly dependent on context, but insights from EPA's enforcement program are likely to be particularly valuable more broadly for various reasons, including the agency's extensive experience, accumulated over more than forty years under different pollution control statutes, in fostering compliance; the challenges posed by the participation of the states in pollution control regimes, which raise federalism issues similar to those facing other agencies; and the evolution of the capacities of regulatory stakeholders and of the challenges confronting them over time. See, e.g., J. Maria Glover, The Structural Role of Private Enforcement Mechanisms in Public Law, 53 WM. \& MARY L. REV. 1137, 1145 (2012) (discussing a "unified approach to the design of private enforcement mechanisms better tailored to the exigencies of particular regulatory regimes").

${ }^{15}$ For one example of the type of case study that deserves close attention for its insights about enforcement and compliance programs, see e.g., Joe Schieffelin, et al., Colorado's Hazardous Waste Small Quantity Generator (SQG) Self-Certification Program (April 2013) (on file with the authors). NEXT GENERATIOn COMPLIANCE (LeRoy C. 


\section{Effective Regulation: Key Components and Contextual Design Challenges}

In fashioning or refashioning the design of a regulatory program, policymakers strive, among other things, to create mechanisms that are effective in achieving, or at least advancing, the program's goals. ${ }^{16}$ The relative attractiveness of options available to an agency like EPA in structuring and implementing its enforcement and compliance promotion function may depend on the nature of the regulatory program. Numerous models of regulation, and hence effective regulation, exist. For example, in the environmental field, many commentators characterize traditional regulation as "command-and-control." According to Professors Cole and Grossman, "'[c]ommand-and-control' is in essence a regulatory approach whereby the government 'commands' pollution reductions (e.g., by setting emissions standards) and 'controls' how these reductions are achieved (e.g., through the installation of specific pollution-control technologies)." ${ }^{17}$ Other variations include market-based approaches to regulation, 18 "new governance" approaches, ${ }^{19}$ and adaptive regulation. ${ }^{20}$ Each type of regulation has different

Paddock \& Jessica A. Wentz, eds., Envtl Law Inst., 2014) [hereinafter NeXT GENERATION COMPLIANCE], collects descriptions and assessments of recent innovative federal and state environmental regulatory enforcement and compliance programs.

${ }^{16}$ Agency "pathologies" and other factors obviously have the potential to affect policymakers' motivations. See Engstrom, supra note 3, at 663-64 (discussing "bureaucratic behavioral pathologies," such as agency capture, agency self-aggrandizement, agencies' predilections for overly cautious behavior, and the influence of careerist incentives of agency personnel, in framing choices among different agency gatekeeping options.) Although there is debate about the effectiveness of our nation's environmental initiatives, it is well accepted both that there have been some successes and that much more remains to be done. See, e.g., Robert Adler, Resilience, Restoration, and Sustainability: Revisiting the Fundamental Principles of the Clean Water Act, 32 WASH U. J.L. \& POL'Y 139, 172 (2010) ( noting that "the [CWA] has resulted in significant progress in improving the quality of the Nation's waters")

${ }^{17}$ Daniel H. Cole \& Peter Z. Grossman, When Is Command-and-Control Efficient? Institutions, Technology, and the Comparative Efficiency of Alternative Regulatory Regimes for Environmental Protection, 1999 WIs. L. REV. 887, 887 n.1 (1999). This definition is misleading for federal environmental mandates that establish performance standards, which dictate the end result regulated entities must achieve (e.g., a certain level of pollution reduction that a regulator determines is achievable using available technology), but not the means of achieving those results. Regulated entities have at least some discretion to select the means. Programs that dictate both the ends and the means are referred to as design standards, which are much rarer than performance standards in federal pollution control law. See, e.g., SidNEy A. SHAPIRO \& ROBERT L. GLICKSMAN, Risk REgUlation AT RISK: RESTORING A PRAGMATIC APPROACH 151-52 (2003); Office of Technology Assessment, Environmental Policy Tools: A User's Guide, OTA-ENV-634 (1995). As others have pointed out, the term command-and-control is a pejorative term whose use arose out an effort by regulated businesses to depict environmental regulation as the product of "overregulation, big government, and bureaucratic zealotry." Richard N.L. Andrews, The EPA at 40: An Historical Perspective, 21 Duke EnVTl. L. \& Pol'y F. 223, 234-35 (2011). See also David M. Driesen \& Amy Sinden, The Missing Instrument: Dirty Input Limits, 33 HARV. ENVTL. L. REV. 65, 76 (2009) (substituting the term "traditional regulation" for "command-and-control regulation" "[t]o avoid confusion and misleading pejorative terminology"). As Cole and Grossman point out, critics of traditional regulation have even equated command-and-control regulation "with 'Soviet-style' regulation and 'socialist central planning,' implying that it is both endemically inefficient and democratically illegitimate." Cole \& Grossman, supra, at 887.

${ }^{18}$ E.g., 42 U.S.C. $\S \S 7651$ to 7651 (emissions trading program to reduce acid rain).

${ }^{19}$ E.g., Karen Bradshaw Schulz, New Governance and Industry Culture, 88 NotRE DAME L. REV. 2515 (2013); Jason M. Solomon, New Governance, Preemptive Self-Regulation, and the Blurring of Boundaries in Regulatory Law and Practice, 2010 WIs. L. ReV. 227; Douglas Nejaime, When New Governance Fails, 70 OнIO St. L.J. 323 (2009); Orly Lobel, Setting the Agenda for New Governance Research, 89 MinN. L. REV. 498 (2004).

${ }^{20}$ E.g., Craig \& Ruhl, supra note 12 (discussing three models of regulation, traditional, market-based, and adaptive). The list in the text of available models of environmental regulation is not exhaustive. For a succinct review of several types of regulation, see Office of Technology Assessment, supra note 17. 
features, and requires different things to work well for it to be effective. ${ }^{21}$ Agencies like EPA may use different types of regulation for different challenges, and they may mix and match different approaches to address concerns as well. ${ }^{22}$

For many types of regulation, enforcement (and compliance with regulatory norms more generally) is often characterized as essential to effective regulation, ${ }^{23}$ although it is not sufficient to achieve desired environmental protection policy objectives. ${ }^{24}$ While recognizing that the particular regulatory approach may affect the choice of enforcement and compliance promotion strategies, at a macro level we suggest that it is possible to identify at least five critical components of an effective regulatory enforcement and compliance function. Section A below introduces and reviews these components. Section B considers some of the complexities involved in fitting each of these components into particular regimes, including the synergies they provide and the need to make difficult trade-offs when they threaten to work at cross-purposes. Section $\mathrm{C}$ then introduces four challenges that further contextualize the task of designing the appropriate structure and content of an agency's enforcement and compliance promotion function.

\section{A. Five Key Components of Effective Regulation}

Although it is possible to describe the components of effective regulation in many ways, ${ }^{25}$ we think at least five features are relevant to the design of a successful regulatory enforcement and compliance program: norm clarity, norm achievability, compliance

\footnotetext{
${ }^{21}$ See, e.g., Sally S. Simpson et al., An Empirical Assessment of Corporate Environmental Crime-Control Strategies, 101 J. CRIM. L. \& CRIMINOLOGY 231, 237-38 (2013) (describing different features of command-and-control and self-regulation); Craig \& Ruhl, supra note 12, at 20-21 (suggesting that the type of regulation used may affect the salience of its attributes). Definitions of "effectiveness" vary based not only on the tools or strategies to be used in a particular regulatory scheme, but also on regulatory goals.

${ }^{22}$ For example, under the CWA, EPA uses all of the types of regulation discussed in the text to restrict discharges of pollutants.

${ }^{23}$ Congress, regulators, and scholars have all subscribed to this view. See, e.g., EPA, Environmental Enforcement, supra note 6, at 1 ("Without compliance, environmental requirements will not achieve the desired results."); Auditor General Report, supra note _ (noting that the Canadian counterpart to EPA, Environment Canada, similarly has concluded that "environmental laws alone are not enough to guarantee a cleaner, better environment. These laws also need to be enforced."); Markell, Deterrence-Based Enforcement, supra note 1. See also Barton H. Thompson, Jr., The Continuing Innovation of Citizen Enforcement, 2000 U. ILL. L. REV. 185, 189 ("Strong environmental laws are meaningless unless they are effectively enforced."); Thomas O. McGarity, When Strong Enforcement Works Better than Weak Regulation: The EPA/DOJ New Source Review Enforcement Initiative, 72 MD. L. REV. 1204, 1206 (2013) (describing "what can be accomplished when a regulatory agency and [the Department of Justice] are willing to devote substantial resources to a coordinated deterrence-based enforcement initiative").

Some "regulatory" design approaches may not include an enforcement component at all or it may be quite remote or understated, such as EPA's 33/50 strategy. For descriptions of that program, see U.S. Environmental Protection Agency, Office of Pollution Prevention and Toxics, 33/50 Program: The Final Record, EPA-745-R-99004 (March 1999), available at http://www.epa.gov/opptintr/3350/3350-fnl.pdf; Madhu Khanna \& Lisa A. Damon, EPA's Voluntary 33/50 Program: Impact on Toxic Release and Economic Performance of Firms, 37 J. ENVTL. ECON. \& MGMT. 1 (1999).

${ }^{24}$ See Cynthia Giles, Next Generation Compliance, 30 EnVTL. F. 22, 23 (2013) (noting that "[w]hile enforcement is an essential part of EPA's compliance program, it is not realistic to think that enforcement alone will get us to the levels of compliance envisioned by our rules").

${ }^{25}$ See supra note 6.
} 
verifiability, an appropriate mix of sanctions and rewards, and indicia of legitimacy, as we illustrate in Table $1 .{ }^{26}$

Table 1 - Components of Effective Regulation

\begin{tabular}{|l|}
\hline Norm Clarity \\
\hline Norm Achievability \\
\hline Verifiability \\
\hline The Mix of Rewards and Sanctions \\
\hline Indicia of Legitimacy \\
\hline
\end{tabular}

\section{Clarity}

It is axiomatic that it is important to consider the clarity of regulatory norms in designing effective regulations. ${ }^{27}$ There are good reasons for regulators to strive for clarity and certainty and to create clear expectations for acceptable (and unacceptable) conduct. It is difficult for a regulated entity to comply with its regulatory responsibilities, or for others to assess whether it has done so, without understanding what those responsibilities are. Participants across the spectrum of interested stakeholders recognize the value of establishing clear standards for regulated parties to meet. Complaints about indeterminacy are heard from regulated parties as well as members of the public. ${ }^{28}$ The government has internalized this message as well, with the head of EPA's enforcement office recently acknowledging that "we should focus on greater simplicity and clarity [in our regulations]. One of the principles we have learned over years of

\footnotetext{
${ }^{26}$ One could easily compartmentalize the features of the regulatory process differently, even if one were to agree with the thrust of our effort. For example, our first two categories overlap to some degree, though we think they are sufficiently distinct to deserve separate treatment. Similarly, one could separate the carrot and stick-oriented approaches to promoting compliance, which we have combined in our fourth component. Additionally, we have not created a separate element to acknowledge the options for self-regulation that play an increasingly important role. Some might break out fairness as a separate component of effective regulation. We think perceptions of fairness (or lack thereof) in terms of the distributional effects of regulation affect regulatory legitimacy, and we therefore treat fairness as an aspect of legitimacy. Finally, achieving desired results is obviously one of the indicia of effectiveness. Our typology is intended to provide a big picture sense of different key components of an effective regulatory process. We believe our framework for integrating the contextual challenges discussed in Part IC into the design of enforcement and compliance programs would remain valuable even if one were to define the key components of effective regulation differently than we have.

${ }^{27}$ See, e.g., Auditor General Report, supra note 3, at 6 (noting that a "range of activities contributes to compliance . . . , including drafting regulations that are enforceable ...." and further noting that "enforceability" "depends on a number of factors, including clear language and definitions ...").

${ }^{28}$ At the far end of the continuum are cases such as General Elec. Co. v. EPA, 53 F.3d 1324, 1333-34 (D.C. Cir. 1995), in which the D.C. Circuit rejected an EPA enforcement action because EPA's rules did not provide sufficiently clear norms. Probably more typically, lack of clarity leads to delays and increases in transaction costs, and may discourage socially worthwhile activity. See Angela Morrison Uhland, Improving Regulations for Biomass-Based Electrical Generating Facilities, 23 NAT. RESOURCES \& ENV'T 15 (2008). The more likely the possible enforcement, and the more burdensome any sanctions assessed would be, the more likely indeterminacy will have these effects.
} 
hard experience is that compliance is better when the rules are simple and clear." 29 This message is most obviously salient for the development of regulations, ${ }^{30}$ but it is also important in the development of guidance and the exercise of enforcement discretion. ${ }^{31}$

Achieving or pursuing clarity requires attention during multiple stages of the regulatory process. An obvious starting point is the regulatory norms themselves. A second important aspect of clarity, however, involves education, especially education of the regulated community. Studies have shown that taking the extra effort to educate regulated parties about their legal obligations can pay significant dividends in terms of improved compliance. A recent Colorado compliance initiative involving hazardous waste rules, for example, found that an innovative state effort to increase understanding of regulatory requirements led to significant improvements in compliance, thereby dramatically reducing the need for enforcement. ${ }^{32}$

Clarity, however, also may come at a cost. Statutory and regulatory schemes often cover a large number of actors, and not all are situated similarly. Thus, choices often need to be made about whether to use one-size-fits-all approaches or, alternatively, to tailor treatment of different sub-groups within the regulated community. In some situations it is possible to use fairly bright lines for such tailoring. RCRA's use of thresholds to distinguish between standard generators and de minimis generators is an example. ${ }^{33}$ Sometimes, however, efforts to regulate "fairly"

${ }^{29}$ Giles, supra note 24, at 24. See also Water Quality Standards Regulatory Clarifications, 78 Fed. Reg. 54,517, 54,521 (proposed Sept. 4, 2013) (to be codified at 40 C.F.R. pt. 131) (highlighting the value of "clear regulatory requirements" and transparency in promoting water quality protection). Certainty can also help the government perform its responsibilities more efficiently and effectively. See, e.g., EPA OFFICE OF ENFORCEMENT AND COMPLiance AsSurance, CleAn WATER ACt ACTION Plan at 4 (2009) [hereinafter, EPA, CWAP] (noting that EPA's challenges in protecting water quality have been increased by judicial decisions concerning the scope of the CWA's coverage because the "confusion and uncertainty" they created "have negatively impacted EPA's ability to enforce by significantly increasing the amount of time and resources it takes to bring enforcement actions"). Professor Craig, addressing this uncertainty, argues that "[1]egal clarity, certainty, and uniformity are recognized rule-of-law values, particularly when the law seeks to regulate private conduct." Robin Kundis Craig, Agencies Interpreting Courts Interpreting Statutes: The Deference Conundrum of a Divided Supreme Court, 61 EMORY L.J. 1, 5 (2011).

${ }^{30}$ See, e.g., Vincent Di Lorenzo, Principles-Based Regulation and Legislative Congruence, 15 N.Y.U. J. LEGIS. \& PUB. POL'Y 45, 89 (2012) (citing research that "demonstrates that certainty in statutory or regulatory mandates increases the likelihood of compliance").

${ }^{31}$ For an interesting case study, see Melissa K. Scanlan \& Stephanie Tai, Marginalized Monitoring: Adaptively Managing Urban Stormwater, 31 UCLA J. ENVTL. L. \& POL'Y 1 (2013). See also Elizabeth Glass Geltman \& Andrew E. Skroback, Reinventing the EPA to Conform with the New American Environmentality, 23 CoLUM. J. ENVTL. L. 1, 53 (1998) (urging creation of a "no action" process in which EPA would provide facility-specific guidance "so that it gives industry a higher degree of certainty than the EPA's existing guidance documents and policy letters"); Joan H. Krause, Fraud in Universal Coverage: The Usual Suspects (and Then Some), 55 U. KAN. L. REV. 1151, 1156 (2007) (arguing that greater clarity in regulatory guidance may be more effective than higher penalties in reducing undesirable activities concerning health care insurance); $c f$. Amy L. Stein, Reconsidering Regulatory Uncertainty: Making a Case for Energy Storage, 41 F.S.U. L. REV. (forthcoming 2014) (arguing that "not all uncertainty is created equal"), available at http://papers.ssrn.com/sol3/papers.cfm?abstract id=2294056.

${ }^{32}$ Schieffelin, et al., supra note 15; U.S., EPA Increasing Understanding of Environmental Requirements is the Heart of EPA Assistance (2008), available at http://www.epa.gov/compliance/resources/reports/assistance/08cafactsheet.pdf (describing successful education programs which reduced emissions from paint stripping and coating operations and partnerships between EPA and states to increase understanding of industry best waste management practices); U.S. EPA, The National Nitrate Compliance Initiative (2002) (describing a compliance assistance initiative involving the metal finishing sector). 3340 C.F.R. § 261.5 (describing conditional exemption for small quantity waste generators). 
require much more ad hoc judgments about whether particular members of the regulated community qualify for special treatment. Especially in the latter situations, where there are no bright line rules or tests, there is a clear tension between clarity and "fair" treatment. ${ }^{34}$

Regardless of the precise weight policy makers and others attach to clarity as a component of effective regulation in a particular context, it seems relatively uncontested that clarity of norms and expectations is a factor that at a minimum deserves attention in regulatory design. $^{35}$

\section{Achievability}

A second key component of effective regulation is implementability or achievability of requirements. Using EPA's terminology, achievability involves the extent to which strategies "will work in the real world - rules with compliance built in." 36 A recent example of EPA's emphasis on achievability in developing a particular regulatory regime relates to the agency's proposal of emission control regulations for oil and gas producers under the Clean Air Act (CAA). EPA adopted the strategy of allowing producers simply to inform EPA that they are using air pollution control equipment that EPA has certified rather than testing the equipment themselves. EPA explained that its purpose in using this approach was to "make compliance easier and less costly, while improving results . . ..,37

Achievability has not always trumped other values in policy design. Congress has insisted that regulatory standards be set with little if any attention given to achievability because of the weight it attached to other values, such as attaining a particular level of health or environmental protection. In the environmental laws, for example, Congress in some cases has directed EPA not to consider costs in developing regulatory standards. ${ }^{38}$ In other regulatory schemes, Congress did not prohibit consideration of cost, but nevertheless made it clear that it was permissible for EPA to attach relatively little weight to it, and apply a relatively loose definition of achievability. ${ }^{39}$ At least in some contexts, technology-forcing regulatory

\footnotetext{
${ }^{34}$ Some of the waiver provisions under the CWA are examples of regulation that require ad hoc judgments. On the potential benefits of making case-by-case adjustments to regulations after adoption, including through the enforcement process, see Robert L. Glicksman \& Sidney A. Shapiro, Improving Regulation through Incremental Adjustment, 52 KAN. L. REV. 1179 (2004).

35 The rule of lenity is a canon of construction that highlights the value courts have attached to clarity, particularly in criminal prosecutions. See United States v. Bass, 404 U.S. 336 (1971). See also Arizona v. Roberson, 486 U.S. 675, 681 (1988) (highlighting the benefits of a bright line rule which provides "clear and unequivocal guidelines to the law enforcement profession").

${ }^{36}$ Giles, supra note 24, at 23. For arguments in favor of pragmatic regulatory approaches, see SHAPIRO \& GLICKSMAN, supra note 17 . There is obviously an overlap between this second attribute and certainty in that clear rules may be easier to achieve than unclear ones.

${ }^{37}$ Giles, supra note 24, at 23. We do not mean to suggest that self-reporting without agency oversight would necessarily be appropriate. See, e.g., Schieffelin et al., supra note 15 (noting that self-reporting in tandem with agency oversight helped to improve compliance).

${ }^{38}$ See, e.g., Whitman v. Am. Trucking Ass'ns, Inc., 531 U.S. 457 (2001) (holding that the CAA prohibits EPA from considering cost in setting national ambient air quality standards).

${ }^{39}$ E.g., Ass'n of Pacific Fisheries v. EPA, 615 F.2d 794, 808-09 (9 $9^{\text {th }}$ Cir. 1980) (acknowledging that Congress adopted stringent technology-based regulations that might put some regulated sources out of business); Union Elec. Co v. EPA, 427 U.S. 246, 260 (1976) (quoting S. Rep. No. 91-1196, at 2-3 (1970)) ("Therefore, the Committee determined that existing sources of [air] pollutants either should meet the standard of the law or be closed down.").
} 
approaches have been used successfully to substantially improve normatively-desired outcomes notwithstanding questions at the outset about the achievability of such approaches. ${ }^{40}$

Beyond the scope of any particular regime, scholars have debated the value of including hortatory language in environmental statutes because of the gap between objectives and likely results. Some suggest that setting the bar high has had a positive influence on performance. ${ }^{41}$ Others have been more skeptical. ${ }^{42}$ Regardless of the weight that should be attached to achievability in the design of any particular regulatory regime, the larger, conceptual point is that it is important to consider the extent to which regulated parties are likely to be able to achieve regulatory standards in development of regulatory approaches.

\section{Verifiability}

A third key component of effective regulation and of strategies to induce compliance involves what we term "verifiability." We define verifiability as the capacity to monitor compliance with regulatory requirements. There is little question that the ability to monitor compliance with legal requirements is a critical component of effective regulation. ${ }^{43}$

The major federal environmental regulatory statutes generally provide broad monitoring authority that includes, at a minimum, authority for the government to inspect an operation's

\footnotetext{
${ }^{40}$ Technology-forcing regulation has long been an accepted and important tool for achieving environmental goals. Aspirational regulations have prompted technological developments that facilitated improved performance, sometimes in the face of infeasibility claims. See Thomas O. McGarity, Radical Technology-Forcing in Environmental Regulation, 27 LOY. L.A. L. REV. 943 (1994); Robert L. Glicksman, Anatomy of Industry Resistance to Climate Change: A Familiar Litany, in EConomic Thought And U.S. Climate Change Policy (David M. Driesen ed., The MIT Press 2010); Daniel P. Selmi, Impacts of Air Quality Regulation on Economic Development, 13-Fall NAT. RESOURCES \& ENV'T 382, 386 (1998) ("In the past, claims that the pollution control technology is impossible to achieve have collapsed when one manufacturer announced that it was able to comply.”).

${ }^{41}$ See, e.g., Michael M. O'Hear, Sentencing the Green-Collar Offender: Punishment, Culpability, and Environmental Crime, 95 J. CRIM. L. \& CRIMINOLOGY 133, 150 (2004) (noting that many environmental laws with aspirational objectives "have arguably forced much beneficial technological and social change").

${ }^{42}$ Compare John P. Dwyer, The Pathology of Symbolic Legislation, 17 ECOLOGY L.Q. 233, 300 (1990) ("Symbolic legislation is not a set of specific instructions for the agency to follow, but a statement of legislative aspirations and assurances delivered to various constituencies as well as the agency.”); Lincoln L. Davies, Reconciling Renewable Portfolio Standards and Feed-in Tariffs, 32 UTAH EnVTL. L. REV. 311, 326-27 (2012) (raising possibility that renewable portfolio standards have operated as "political subterfuges: symbolic legislation adopted to garner electoral favor but intended to accomplish very little in actuality"); Steve R. Johnson, The Dangers of Symbolic Legislation: Perceptions and Realities of the New Burden-of-Proof Rules, 84 IowA L. REV. 413, 446-58 (1999), with Christopher T. Giovinazzo, Defending Overstatement: The Symbolic Clean Air Act and Carbon Dioxide, 30 HARV. ENVTL. L. REV. 99, 119 (2006) (noting the instrumental value of symbolic legislation, which can "function as a 'thumb on the scale' in favor of more rather than less pollution control. [Such] symbolism, though imperfect, is a rational legislative approach to states' and industries' persistent resistance to cleaning the air.").

${ }^{43}$ See, e.g., Auditor General Report, supra note 1, at 9-10; U.S. EPA, Office of Inspector General, The EPA Should Improve Monitoring of Controls in the Renewable Fuel Standard Program 6 (2013), available at http://www.epa.gov/oig/reports/2013/20130905-13-P-0373.pdf (recommending additional monitoring to verify that participants comply with regulations and to avoid fraud cases); U.S. EPA, Office of Inspector General, EPA Needs to Direct More Attention, Efforts, and Funding to Enhance its Speciation Monitoring Program for Measuring Fine Particulate Matter, 3 (2005), available at http://www.epa.gov/oig/reports/2005/20050207-2005-P-00004.pdf (describing the EPA's speciation monitoring network as a "critical component" for developing control strategies); U.S. GAO, Environmental Enforcement: EPA Cannot Ensure the Accuracy of Self-Reported Compliance Monitoring Data 15 (1993), available at http://www.gao.gov/products/RCED-93-21 (describing an initiative to identify hazardous waste programs operating without self-reporting as vital to the integrity of the regulatory system).
} 
compliance with regulatory requirements as well as an obligation for the regulated party to monitor its own performance. ${ }^{44}$ Yet, monitoring schemes come in various shapes and sizes. ${ }^{45}$ One of us was involved many years ago in establishing a statewide strategy that sought to enhance verifiability by requiring facilities with especially significant compliance concerns to hire independent third-party monitors whose role was to complement both government inspection efforts and the facility's own compliance efforts. ${ }^{46}$

As a practical matter the nature and extent of monitoring that occurs is likely to depend on a variety of features of the particular regulatory regime involved, including the availability of government resources; the complexity associated with monitoring compliance and the training required to monitor credibly; the availability, cost, and reliability of monitoring equipment; the trustworthiness of regulated parties and their commitment to self-monitoring; and the capacity of non-governmental interests to participate in monitoring.

Some commentators have highlighted the importance of broader transparency to the public as an aspect of verifiability. ${ }^{47}$ Transparency can be enhanced in a variety of ways. For example, the Clean Water Act requires permittees to submit discharge monitoring reports (DMRs) that demonstrate (non-)compliance with legal requirements and requires that these DMRs be easily accessible to interested citizens. The transparency of the CWA in revealing non-compliance is a principal reason most of the citizen suit activity against alleged violators of the major environmental laws has occurred under that statute. ${ }^{48}$ Other reporting requirements,

\footnotetext{
${ }^{44}$ E.g., 33 U.S.C. $\S 1318$ (CWA); 42 U.S.C. § 6927 (Resource Conservation and Recovery Act (RCRA)); 42 U.S.C. $\S 7414$ (CAA).

${ }^{45}$ Monitoring can take several forms, such as the requirement that regulated entities file periodic discharge monitoring reports (DMRs), as under the CWA, see 40 C.F.R. $\S \S 122.2$ (defining DMRs), 122.41(l)(4)(i), or the obligation for industrial facilities to report annual chemical releases under the Emergency Planning and Community Right-to-Know Act. See U.S. EPA, Toxic Release Inventory Program, available at http://www2.epa.gov/toxicsrelease-inventory-tri-program. DMRs are compliance-based, while chemical release forms are not strictly so but can indirectly assist environmental performance generally and compliance in particular. Verifiability tools vary in their degree of transparency.

${ }^{46}$ See David L. Markell, States and Innovators: It's Time for a New Look to Our “Laboratories of Democracy” in the Effort to Improve Our Approach to Environmental Regulation, 58 ALB. L. REV. 347, 408 (1994). Other approaches include reward systems, U.S. EPA, Performance Track Program Guide 2 (Sept. 2005); compliance incentives, U.S. EPA, Operating Principles for an Integrated Enforcement and Compliance Assurance Program 8 (Interim Final Nov. 18, 1996); and spotlighting and information dissemination, Cass Sunstein, Informational Regulation and Informational Standing: Akins and Beyond, 147 U. PA L. REV. 613, 616 (1999).

47 See David L. Markell, "Slack" in the Administrative State and its Implications for Governance: The Issue of Accountability, 84 OR. L. REV. 1, 8-10 (2005) [hereinafter Markell, Slack] (discussing increases in transparency and public involvement). EPA's view is that “[p]ublic disclosure is [an] underutilized tool: there is powerful evidence that publishing information about company performance drives better behavior, as pressure is applied by customers, neighbors, investors, and insurers." Giles, supra note 24, at 24. Further, Giles indicates that transparency may serve a "reminder function" by drawing attention to problems and inducing senior-level officials to fix them. Id. Transparency also may bring community pressure to bear on lower performing parties and alert investors and insurers in ways that provide financial motivation to improve performance. Id. at 25-26.

${ }^{48}$ See, e.g., James R. May, Now More than Ever: Trends in Environmental Citizen Suits at 30, 10 WIDENER L. REV. 1, 2 (2003) (noting that most environmental citizen suits between 1978 and 1983 were filed under the CWA, although suits were distributed more evenly in later years); William L. Andreen, Motivating Enforcement: Institutional Culture and the Clean Water Act, 24 PACE ENVT L. REV. 67, 75 (2007) [hereinafter Andreen, Motivating Enforcement] (reporting that environmental NGOs brought hundreds of CWA cases during the Reagan administration when federal enforcement flagged).
} 
such as those for hazardous substance releases above a reportable quantity, ${ }^{49}$ or pursuant to EPA's toxics release inventory (TRI) program, ${ }^{50}$ are useful for monitoring and verifying compliance with legal requirements while also serving other purposes. ${ }^{51}$

Considerable evidence shows that in many circumstances inadequate verification contributes to lower-than-desired levels of compliance with environmental requirements. To offer an example from the sphere of international environmental law, the Kyoto Protocol's Clean Development Mechanism has suffered from weak verifiability, which has undermined the effectiveness of the Mechanism. ${ }^{52}$ The Canadian Auditor General similarly found that monitoring shortcomings weakened the enforcement and compliance performance of a Canadian environmental program. ${ }^{53}$ On the other hand, enhanced reporting has led to dramatically improved compliance in some cases. In a recent article, EPA's Assistant Administrator for Enforcement highlighted a 2008 study in Massachusetts that found that drinking water systems required to mail compliance information to customers reduced both violations and severe health violations significantly as a result. ${ }^{54}$ She noted that "EPA's efforts to make our data more available are only starting to scratch the surface of the ways transparency can improve results." 55

In short, while the optimal parameters for incorporating a verification component into a particular regulatory regime will depend on a wide variety of factors, the literature demonstrates that verification is a foundational element of an effective regulatory scheme.

\section{The Mix of Rewards and Sanctions}

A fourth component of an effective regulatory scheme is its capacity to incentivize regulated parties to comply with regulatory obligations through the use of both carrots and sticks. Not every violation is worth pursuing, even in a world free of resource constraints. Conceptually, an optimal level of compliance maximizes net social benefits. ${ }^{56}$

\footnotetext{
${ }^{49}$ See, e.g., 42 U.S.C. § 9603 (reporting requirement under CERCLA).

5042 U.S.C. § 11023.

${ }^{51}$ David L. Markell, The Federal Superfund Program: Proposals for Strengthening the Federal/State Relationship, 18 WM. \& MARY J. ENVTL. L. 1, 82 (1993) (citing Charles L. Elkins, Toxic Chemicals, the Right Response, N.Y. TIMES, Nov. 13, 1988, at F3) (stating that the TRI program revealed the extent which companies were discharging potentially harmful substances in both accidents and routine daily operations).

52 See, e.g., Alan Ramo, The California Offset Game: Who Wins and Who Loses?, 20 Hastings W.-N.W. J. ENVTL. L. \& POL'Y 109, 121 (2014) (“The CDM has suffered serious [verifiability] problems. Determining whether emissions have actually increased is easy if you have continuous and automatic emissions monitoring that can be verified. In a developing country where one relies upon records that may not exist, and testing technology that may be inadequate or fraudulent, it can be difficult if not impossible.").

53 Auditor General Report, supra note 3, at 2.

${ }^{54}$ Giles, supra note 24 , at 24

55 Id. at 25-26.

${ }^{56}$ See Daniel A. Farber, Taking Slippage Seriously: Noncompliance and Creative Compliance in Environmental Law, 23 HARV. ENVTL L. REV. 297, 316 (1999); Engstrom, supra note 3, at 630 (citing Becker, supra note 2, at 200, as the source of "the classic account of optimal deterrence in which sanctions are set equal to the net social cost of undesirable conduct divided by the probability of successful prosecution, such that a wrongdoer internalizes the full social cost of her action").
} 
EPA, on its own and in tandem with environmental or community NGOs and regulated parties, has a rich array of options. ${ }^{57}$ These include litigation options such as criminal prosecutions under many of the environmental statutes, civil judicial actions, and administrative enforcement actions, some of which may, like their judicial counterparts, seek penalties and other relief. $^{58}$ Beyond these types of formal enforcement litigation, EPA uses strategies that employ "carrots" or a mix of "carrots and sticks" to promote compliance. ${ }^{59}$ An active debate continues about the relative effectiveness of different strategies in different contexts. ${ }^{60}$

At the ground level, EPA has developed a library full of enforcement response and penalty policies that seek to prioritize violations that warrant different levels of enforcement attention. ${ }^{61}$ The agency has generally attempted to focus on "significant violations" and "high priority" violations and give less or different types of attention to minor instances of noncompliance. ${ }^{62}$ It has also developed a substantial set of compliance promotion and incentive policies that reflect a mix of strategies. ${ }^{63}$

\footnotetext{
57 Jon D. Silberman, Does Environmental Deterrence Work? Evidence and Experience Say Yes, But We Need to Understand How and Why, in MAKING LAW WORK: ENVIRONMENTAL COMPLIANCE \& SUSTAINABLE DEVELOPMENT 384 (Durwood Zaelke et al. eds, 2005) [hereinafter MAKING LAW WORK] (describing actions EPA can use, including civil and criminal enforcement, penalties, injunctive relief, public notification of violations, and varying incentives). Following up to assess whether alleged violators return to compliance is another aspect of enforcement. Auditor General Report, supra note 3, at 2.

${ }^{58}$ See, e.g., 33 U.S.C. § 1319 (CWA); 42 U.S.C. 6928 (RCRA); 42 U.S.C. § 7413 (CAA).

${ }^{59}$ See Lyon, supra note 3, at 49-52 (discussing the impacts of alternative policy instruments, such as subsidies and effluent fees); Robert Esworthy, Federal Pollution Control Laws: How Are They Enforced?, Congressional Research Service Report 19 (June 18, 2013), available at https://www.fas.org/sgp/crs/misc/RL34384.pdf [hereinafter Esworthy, How Are They Enforced?] (noting that EPA uses a diverse set of strategies to promote compliance, including compliance assistance, administrative and civil enforcement, and criminal enforcement); Envtl. Law Inst., Beyond Enforcement? Enforcement, Compliance Assistance, and Corporate Leadership Programs in Five Midwest States (January 2003); Incentives for Self-Policing: Discovery, Disclosure, Correction and Prevention of Violations, 65 Fed. Reg. 19,618 (April 11, 2000). The Occupational Safety and Health Administration (OSHA) experimented with an apparently successful program under which it promised less frequent inspection of plants with poor safety records whose operators voluntarily agreed to improve working conditions and monitor and report on their progress. A court invalidated the program, however, based on the agency's procedural violations in adopting it. See Mark Seidenfeld, An Apology for Administrative Law in the Contracting State, 28 FLA. ST. U. L. REv. 215, 218 \& n.12 (2000) (citing Chamber of Commerce of the U.S. v. Dep't of Labor, 174 F.3d 206 (D.C. Cir. 1999)).

${ }^{60}$ Mark A. Cohen, Empirical Research on the Deterrent Effect of Environmental Monitoring and Enforcement, 30 EnVTL. L. REP. 10245 (2000); Jon D. Silberman, Does Environmental Deterrence Work? Evidence and Experience Say Yes, But We Need to Understand How and Why, 30 ENVTL. L. REP.10523 (2000); Simpson et al., supra note 21, at 233 (noting that scholars and policymakers know little about effectiveness of different corporate crime-control strategies).

${ }^{61}$ E.g., U.S. EPA, RCRA Civil Penalty Policy (June 2003), available at http://www2.epa.gov/enforcement/resourceconservation-and-recovery-act-rcra-civil-penalty-policy; Revision to Adjusted Penalty Policy Matrices Package Issues on November 16, 2009, available at http://www2.epa.gov/enforcement/revision-adjusted-penalty-policymatrices-package-issued-november-16-2009 ; U.S. EPA, Workbook: Timely and Appropriate Enforcement Response to High Priority Violations (HPVs) (1999), available at http://www2.epa.gov/enforcement/workbooktimely-and-appropriate-ta-enforcement-response-high-priority-violations-hpvs. For current EPA efforts to revisit CWA enforcement efforts, see Part III infra.

${ }^{62}$ See, e.g., Memorandum: Revision of NPDES Significant Noncompliance (SNC) Criteria to Address Violations of Non-Monthly Average Limits, September 21, 1995, available at http://www2.epa.gov/enforcement/memorandumrevision-npdes-significant-noncompliance-snc-criteria-address-violations-non.; David M. Uhlmann, After the Spill Is
} 
Taking a step back conceptually from our review of the mix of tools available to promote compliance, debate continues about the appropriate metrics for evaluating enforcement performance. The possibilities include inputs (e.g., the extent of agency resources invested in bringing enforcement cases), outputs (e.g., the number of enforcement actions brought), outcomes (e.g., the amount of pollution reductions achieved through enforcement actions), and environmental results (e.g., changes in the quality of the ambient air or water because of enforcement activity). ${ }^{64}$ Compliance levels have been considered the holy grail by some, ${ }^{65}$ but have proven extremely difficult to use in practice. ${ }^{66}$

\section{Legitimacy}

Finally, we suggest that an important component of effective regulation is its capacity to promote legitimacy, which we define to include enhancing confidence by the public and others. ${ }^{67}$ We believe that, in designing and implementing regulatory enforcement and compliance mechanisms, it is appropriate for policymakers to ask questions about the effects of different design options on public perceptions. Will a particular regulatory design enhance or diminish public confidence in a regulatory program and the government's ability and willingness to promote compliance with it? A regulatory scheme that leads to a public perception that government is corrupt, overbearing, or selective in its enforcement of the law may lead to a loss of confidence and trust that undermines effective regulation in many ways, including by

Gone: The Gulf of Mexico, Environmental Crime, and Criminal Law, 109 Mich. L. REV. 1413, 1459 (2011) ("The EPA emphasizes cases involving significant harm in its policy regarding the exercise of investigative discretion."). ${ }^{63}$ See, e.g., EPA, Compliance Assistance, http://www.epa.gov/compliance/assistance/index.html.

${ }^{64}$ Shelley H. Metzenbaum, Strategies for Using State Information: Measuring and Improving State Performance 20-21 (IBM Center for The Business of Government 2003) (summarizing recent emphasis on outcome indicators for performance rather than process); National Academy of Public Administration, Evaluating Environmental Progress: How EPA and the States Can Improve the Quality of Enforcement and Compliance Information 10 (2001) ("The primary accountability mechanism used by Congress and EPA [for the states] has ... been counting activities that states provide for EPA's media-specific databases, such as numbers of permits, inspections, enforcement actions, and penalty dollars."); Joel A. MintZ, ENFORCEMENT AT THE EPA: HigH STAKES AND HARD CHOICES 119 (1995) (noting that EPA evaluation of its enforcement work is based on numerical indicators).

${ }^{65}$ See Markell, Slack, supra note 47, at 62 ("Many states, among other parties, have identified compliance rates as one of the best measures (and perhaps the best measure) of enforcement performance.").

${ }^{66} \mathrm{Id}$. (noting that "the calculation of such rates in a credible way is a significant challenge") (citing National Academy of Public Administration, Evaluating Environmental Progress: How EPA and the States Can Improve the Quality of Enforcement and Compliance Information 27 (2001), available at http://www.napawash.org/pc economy environment/environmental.pdf).

${ }^{67}$ For efforts to raise this fifth feature of effective regulation in different contexts, see John H. Knox \& David L. Markell, Evaluating Citizen Petition Procedures: Lessons from an Analysis of the NAFTA Environmental Commission, 47 TEX. INT'L L.J. 505 (2012); Hammond \& Markell, supra note 5. For discussions of the difficult-todefine concept of legitimacy, see, e.g., Sidney A. Shapiro et al., The Enlightenment of Administrative Law: Looking Inside the Agency for Legitimacy, 47 WAKE FOREST L. REV. 463, 466 (2012) (noting that "[1] egitimacy is a notoriously treacherous concept."). One way to define the term is to focus on "the acceptability of [a] regulation to those involved in its development." Jody Freeman \& Laura I. Langbein, Regulatory Negotiation and the Legitimacy Benefit, 9 N.Y.U. ENVTL. L.J. 60, 63 (2000). Such acceptability may hinge on the availability of opportunities for public participation and the degree of regulatory transparency. See Rebecca M. Bratspies, A Regulatory Wake-Up Call: Lessons from BP's Deepwater Horizon Disaster, 5 GoldEN GATE U. ENVTL. L.J. 7, 59 n.345 (2011) ("Public participation and transparency are widely considered to be the backbone of legitimacy for public agencies."); Durwood Zaelke, Matthew Stilwell \& Oran Young, What Reason Demands: Making Law Work for Sustainable Development, in MAKING LAW WORK, supra note 57, at 42 (describing elements of good governance for sustainable development as including anti-corruption and accountability). 
exacerbating budget pressures if public support for necessary funding diminishes. ${ }^{68}$ The legitimacy of a regulatory system also may turn on the degree to which it protects against deviation from legislative goals due to capture of regulators by special interests, and on whether decisionmakers are perceived as honest, unbiased, or competent. ${ }^{69}$ Polling results showing the American public's loss of confidence in the federal government highlight the salience of perception by different publics in designing the enforcement aspects of regulatory programs. ${ }^{70}$

\section{B. Inter-Relatedness of the Five Components of Effective Regulation}

The preceding section introduces what we believe to be five important components of effective regulation. ${ }^{71}$ Considering each of these components on its own merits is, we submit, a starting point in designing and implementing an effective enforcement and compliance promotion regime. A second layer of analysis involves assessing how the relationships among the components affect the manner in which, and the degree to which, policymakers should pursue each individual component of effective regulation. This section focuses on the fundamentally inter-related character of different components of the regulatory process in order to reinforce the importance of considering regulatory design holistically rather than atomistically.

The five components of effective enforcement and compliance that we discuss above are inter-related in a virtually unlimited number of ways. We offer a few illustrations in this section. In 2007, Colorado's hazardous waste program was concerned about compliance rates among small quantity generators (SQGs) of hazardous waste. ${ }^{72}$ As backdrop, state regulators believed that collectively, SQGs in the state might pose a greater risk to human health and the environment than other, larger generators. This was because in the aggregate SQGs generated a considerable amount of waste; they did so at many more locations than large quantity generators; and the SQGs had less control over the waste and lower levels of compliance. Because of

\footnotetext{
${ }^{68}$ Sackett v. EPA, 132 S. Ct. 1367 (2012), in which landowners challenged an EPA order requiring them to apply for a dredge and fill permit under the CWA before developing portions of their land alleged to contain wetlands, may be an example of lack of buy-in by some citizens to regulatory goals or means. The controversy concerning the IRS's purported selection bias in targeting "tea party" groups is another recent example. See Sheila Krumholz \& Robert Weinberger, The Real I.R.S. Scandal, N.Y. TIMES, May 15, 2013, at A27 (noting long-term damage to IRS credibility in assessing claims of tax-exempt status that "will be difficult to undo"); Rachel E. Barkow, Prosecutorial Discretion: Prosecutor Bias and the Department of Justice, 99 VA. L. REV. 271 (2013) (raising concerns about unfettered prosecutorial discretion). See also supra note 26 (discussing fairness as a component of legitimacy).

69 See Camacho \& Glicksman, supra note 5, at 29-31.

${ }^{70}$ See e.g., Joy Wilke \& Frank Newport, Fewer Americans than Ever Trust Government to Handle Problems, GALLUP POLITICS, Sept. 13, 2013, available at http://www.gallup.com/poll/164393/fewer-americans-ever-trust-govhandle-problems.aspx. Some individual agencies, including EPA, tend to poll much higher, however. At the same time that only $19 \%$ of respondents in one poll answered that they trust the government to do what is right almost always or most of the time, and only $23 \%$ viewed Congress favorably, $62 \%$ of respondents viewed EPA favorably. Pew Research Center, Trust in Government Nears Record Low, but Most Federal Agencies Are Viewed Favorably (Oct. 18, 2013), available at http://www.people-press.org/files/legacy-pdf/10-1813\%20Trust\%20in\%20Govt\%20Update.pdf

${ }^{71}$ A recent Congressional Research Service (CRS) report notes that "[c]ompliance with pollution control laws is addressed through a continuum of response mechanisms, ranging from compliance assistance to administrative and civil enforcement, to the stronger criminal enforcement." Esworthy, How Are They Enforced?, supra note 59, at 19. In the previous section, we suggest that the continuum is even broader than the report suggests, reaching at least as far back as the initial adoption of regulatory requirements.

72 This summary of the Colorado program is taken from Schieffelin et al, supra note 15.
} 
resource constraints, agency staff were only able to inspect each SQG once every eight years. In the agency's view, "[t]hat [was] simply not enough to improve compliance" - "[t]he 12 percent inspection coverage we were attaining each year did not create enough accountability and deterrence to improve compliance rates."73

Colorado decided it needed to address the SQG sector in a different way. It adopted a regulation that sought to improve compliance by changing the "verifiability" component and enhancing the clarity of the regulatory requirements. In particular, Colorado required that each SQG complete and return a "self-certification checklist" to the agency. Failure to do so subjected a SQG to an enforcement action and the possibility of penalties. Colorado reports that the return rate for the checklists is more than 95 percent.

Beyond tweaking the verifiability component of its regulatory scheme, Colorado also invested considerable effort in improving the scheme's clarity. It prepared a comprehensive compliance checklist that identified all of the regulatory requirements, and it developed an instruction booklet that provided guidance on how to complete each question on the checklist. The state sent the checklist and instruction booklet to all members of the regulated community.

The changes to verifiability, sanctions, and clarity led to significant increases in compliance. As the report on the initiative reflects, "compliance rates across the SQG sector have dramatically improved. . . . In 2008, only 32 percent of the SQGs were in compliance with 100 percent of the regulatory requirements. . . . By 2011, this compliance rate had increased to 84 percent." 74 This example reflects the value of thinking about key components of a compliance promotion scheme in an integrated way and happily appears to be an example of a significant redesign that yielded impressive improvements in performance.

A second example of the value of approaching the different components of regulation in integrated fashion is not as grounded in a real-world effort to improve environmental compliance. In a recent article, Professor David Freeman Engstrom focuses on one aspect of enforcement - enforcement litigation, and in particular private and public enforcement litigation - in an effort to improve regulatory design. ${ }^{75}$ Engstrom considers whether agency "gatekeeping" of private enforcement would help to rationalize enforcement litigation; he further considers the possible options for designing such a gatekeeping function.

For example, Engstrom suggests that a strong agency gatekeeping role to limit or direct private enforcement might be appropriate when there is a significant risk that private enforcement will yield legislative drift "as private enforcers drive law enforcement efforts in new and democratically unaccountable directions. ..."76 It seems reasonable to conclude that the clearer the substantive rules that govern the conduct of regulated entities, the lower the risk that courts, responding to suits by non-governmental organizations (NGO)s, will accept novel applications of legal mandates that amount to such legislative drift. Under these circumstances, all other things being equal, the need for agencies to exercise veto authority over private enforcement efforts should recede. On the other hand, in some cases, clear requirements may contribute to dramatic reductions in non-compliance and hence in the need for enforcement,

\footnotetext{
73 Id. at $4-5$.

${ }^{74} \mathrm{Id}$. at 1.

${ }^{75}$ Engstrom, supra note_3.

${ }^{76}$ Id. at 637-41.
} 
private or public. The value of private enforcement may decline in such circumstances, which might affect analysis of the desired mix of rewards and sanctions and, in particular, the appropriateness of incorporating a private enforcement feature in a compliance program.

The ability of regulated entities to comply with regulatory norms (the achievability component) also is salient in thinking through the desirability and structure of Engstrom's gatekeeping apparatus as part of a regulatory scheme's sanctions function. If compliance is particularly difficult, public enforcers might choose to exercise prosecutorial discretion and defer prosecution of known violations, or reduce the penalties assessed for such violations, perhaps in return for commitments by regulated entities to sink resources into developing a fix for the implementation problem. ${ }^{77}$ A gatekeeper regime that empowered NGOs to initiate private enforcement actions might interfere with commitments that regulated entities might otherwise make to public enforcers. ${ }^{78}$ In circumstances in which achievability is a concern, the arguments in favor of a strong public gatekeeping role for private enforcement actions may be relatively appealing. ${ }^{79}$ On the other hand, problems with achievability may create more, and more significant, non-compliance problems that may overwhelm public enforcement capacity. The incorporation of private enforcement litigation as a component of an enforcement regime would seem to hold special value in such cases. ${ }^{80}$

Consideration of Professor Engstrom's gatekeeping scenario also shows that verifiability is not only a critical feature of regulation in its own right, but is also important because of its effect on other components of regulatory compliance design. Easy and cheap access by private enforcers to information revealing compliance status creates a risk of overdeterrence, at least if one regards what Professor Engstrom refers to as the "zealousness critique" of private enforcement as a significant concern. ${ }^{81}$ If access to information concerning compliance status is available at little if any cost, private enforcers may pursue actions in which their expected return on investment in litigation will exceed their own costs, even if public enforcers would choose not to sue because the expected social cost exceeds the expected social gain. Thus, low verification

\footnotetext{
${ }^{77}$ EPA engages in this practice frequently. See, e.g., Clifford Rechtschaffen, Promoting Pragmatic Risk Regulation: Is Enforcement Discretion the Answer?, 52 U. KAN. L. REV. 1327, 1330-34 (2004) (describing EPA's flexible and pragmatic approach to enforcement, including reliance on investment by regulated entities in supplemental environmental projects).

${ }^{78}$ Michael S. Greve, Private Enforcement, Private Rewards: How Environmental Citizen Suits Became an Entitlement Program, in Environmental Politics: Public Costs, Private RewARds (Michael S. Greve \& Fred L. Smith, Jr. eds., 1992); Michael S. Greve, The Private Enforcement of Environmental Law, 65 TUL. L. REV. 339 (1990).

${ }^{79}$ See infra Part IA4 for discussion of gatekeeping as part of the mix of rewards and sanctions component of effective regulation.

${ }^{80}$ This was Congress's reasoning in including a citizen suit provision in the CWA. Gwaltney of Smithfield, Ltd. v. Chesapeake Bay Found., Inc., 484 U.S. 49, 60 (1987).

${ }^{81}$ Engstrom, supra note 3, at 630-34 (suggesting that private enforcers may be overzealous because their motivations may differ from goal of maximizing social welfare). Engstrom is not alone in identifying the hazards of reliance on private enforcement. See, e.g., Peter Grabosky, Beyond Responsive Regulation: The Expanding Role of Non-State Actors in the Regulatory Process, 7 REG. \& GOVERNANCE 114, 119 (2013) (noting concerns about private regulatory failure, lack of accountability, and private overzealousness). As Grabosky colorfully puts it, "the sword of citizen participation is two-edged. One would not wish to see the advent of wiki witch hunts." Id. at _ . See also Timur Kuran \& Cass R. Sunstein, Availability Cascades and Risk Regulation, 51 STAN. L. REV. 683 (1999).
} 
costs may increase the risk that public and private assessments of the relative costs and value of enforcement diverge, resulting in over-expenditure of social resources and over-deterrence. ${ }^{82}$

The likelihood of overzealousness remains in dispute, however, and gatekeeping regimes may be structured to minimize it (if, indeed, they are needed at all). For example, the absence of a damage remedy for successful private enforcers under the citizen suit provisions of the federal environmental statutes should minimize this risk. Likewise, these provisions all require that penalties by paid to the United States Treasury, not to private enforcers. ${ }^{83}$ Further, some scholars, such as Professor Barton Thompson, have suggested that "the benefits of citizen suits have far outstripped the benefits that Congress originally identified," 84 even assuming that some over-deterrence occurs, because of the potential for private enforcers to create enforcement innovations that may be attractive to public enforcers, the promotion of democratic values that direct citizen participation in law enforcement yields, and the educational value of citizen suits. ${ }^{85}$ The larger point still stands, however: the design of the verifiability component of effective regulation affects how other aspects of environmental regulation should be structured, including the appropriate mix of rewards and sanctions.

A final reflection on the inter-related character of different components of effective environmental regulation relates to the relationship between the mix of sanctions and rewards and legitimacy, and is again illustrated in connection with the desirability of a gatekeeping mechanism. A regulatory design that gives a government agency extremely powerful gatekeeping authority might undermine legitimacy if the public's perception is that an agency is choking off much-needed private enforcement. ${ }^{86}$ Such a loss of legitimacy is most likely to be the case if an agency is widely perceived of as corrupt or captured; extensive opportunities for supplemental private enforcement may help to restore a sense of legitimacy to the regulatory program, and in particular its enforcement component. Less obviously, Professor Engstrom discusses "bubble periods," during which ambiguous regulatory mandates remain unsettled. ${ }^{87}$ He posits that vigorous private enforcement may be troublesome during these transitional periods because judicial responses to private enforcement actions may be difficult to override legislatively and enforcement targets may suffer costly adverse judgments notwithstanding subsequent overrides. In such cases, allowing private enforcement might undermine legitimacy in the eyes of the regulated community at a minimum. This effect would support a strong

\footnotetext{
${ }^{82}$ See Engstrom, supra note 3, at 630-31. See also Seth Davis, Implied Public Rights of Action, 114 COLUM. L. REV. 1, 11, 25 (2014) (describing this problem in connection with implied private rights of action); id. at 46 ("financial incentives may play an important role in the decision to sue, which can lead to excessive litigation and overdeterrence"); Amanda M. Rose, Reforming Securities Litigation Reform: Restructuring the Relationship Between Public and Private Enforcement of Rule 10b-5, 108 COLUM. L. REV. 1301, 1341 (2008) (arguing that, under the securities laws, private enforcers" "profit motive is inherently misaligned with the public's interest in achieving optimal deterrence").

83 See, e.g., 33 U.S.C. §§ 1365(a), 1319(d).

${ }^{84}$ Thompson, supra note 23, at 198. In assessing the zealousness critique, Thompson added that evidence "suggests that environmental nonprofits have filed a sizable number of worthwhile actions that public enforcers either purposefully or unintentionally failed to pursue." Id. at 203. See also id. at 206 (discounting risk of "zealousness error" from citizen suits).

${ }^{85}$ Thompson, supra note 23, at 188.

${ }^{86}$ William Andreen and Sidney Shapiro each suggested this possibility in helpful comments on a draft of this article. See Andreen, Motivating Enforcement, supra note 48, at 84-85 (suggesting that some states filed a significant number of enforcement actions only after a citizen had filed a notice of intent to sue).

${ }^{87}$ Engstrom, supra note 3, at 640.
} 
gatekeeping regime. ${ }^{88}$ But if agency's delay in filling statutory gaps is due not to the costs of regulation but instead to agency disaffection with the statutory regime, private enforcement may help to maintain public confidence in the rule of law. This scenario would seem to favor a weak or nonexistent gatekeeping regime.

\section{Contextual Design Challenges}

The preceding discussion identifies five key components of effective regulation. In addition, it demonstrates that effective design must consider each component as it relates to the others, rather than solely as a distinct and isolated regulatory feature. The following section discusses four contextual issues facing policymakers responsible for regulatory design, which may enrich, and complicate, analysis of how best to craft a program that settles on the best mix of the five components of effective regulation addressed above. ${ }^{89}$ These four contextual design issues are the hybrid character of much of contemporary governance; the need to confront actual performance; the dynamic nature of governance challenges and opportunities; and salience, the need to prioritize in making design and implementation decisions. ${ }^{90}$ We list these elements in Table 2.

Table 2 - Key Design Elements

\section{Hybrid Character of Governance}

Reality checking in terms of past performance and future challenges and opportunities

Dynamic Character

Salience - the need to Prioritize

Figure 1 depicts how the five components of effective regulation described in section A interact with these four contextual design challenges.

[Figure 1 to be added; it will show the interconnectedness of the five components and four contextual design challenges]

In short, as Figure 1 shows, each of the contextual design challenges has the potential to affect one or more components of effective enforcement and compliance promotion. As a result, it is the interaction of the contextual design challenges and the components of effective regulation

\footnotetext{
88 Id. at 639-40.

${ }^{89}$ As is true for virtually all efforts to capture reality through categories, the identity and parameters of the categories are open to question.

${ }^{90}$ We do not claim that these four contextual issues are the only ones relevant to the design of effective enforcement and compliance programs. We believe all four are important to consider, however, in thinking about possible enforcement and compliance promotion options.
} 
that should shape the design of each component of an enforcement and compliance program such as gatekeeping mechanisms. ${ }^{91}$ The remainder of this section elaborates on these interactions.

\section{Hybrid Governance}

One contextual reality of contemporary governance in the United States is its hybrid character. At its most abstract level, we view hybrid government to mean governance "formed or composed of heterogeneous elements."92 Several manifestations of the hybrid character of governance are well known and we mention them only briefly. In terms of horizontal hybrid governance issues, both the U.S. Constitution and the foundational statute for the administrative state, the Administrative Procedure Act, reserve specific roles for the three branches of our federal government. ${ }^{93}$ The ongoing debate about the appropriate role for the Office of Management and Budget (OMB)'s Office of Information and Regulatory Affairs (OIRA) highlights the tension concerning the distribution of power between and among Congress, the President, and federal agencies. ${ }^{94}$ The lack of judicial review of much of what OIRA does raises issues concerning the appropriate role of the judicial branch in presidential review of agency activities as well. More generally, increasing recognition that multiple federal agencies need to be engaged in addressing many of the most significant public policy issues we face today reflects that horizontal coordination challenges exist within, between, and among agencies. These challenges pose a significant barrier to effective governance. ${ }^{95}$

The cooperative federalism structure Congress adopted in enacting the major federal pollution control statutes contributes to the hybrid character of contemporary enforcement and compliance work by giving states a major role in administrative governance. An enormous scholarship addresses the vertical governance challenges the cooperative federalism structure poses, including in the enforcement and compliance realm. ${ }^{96}$ Over the past few years, EPA has acknowledged these challenges and announced renewed efforts to grapple with them more effectively. ${ }^{97}$ The states' central role in the enforcement and compliance promotion function has heavily influenced the design of EPA's programs; this will no doubt continue to be the case for the indefinite future.

Governance is much more than simply the actions of government actors, however, and the quality of governance often benefits (or suffers) from the actions of these multiple

\footnotetext{
${ }^{91}$ Professor Engstrom's focus on rationalization of private and public enforcement litigation as a central challenge of administrative governance illustrates the importance of our first contextual design challenge, hybrid governance. Engstrom, supra note 3.

${ }^{92}$ http://www.thefreedictionary.com/hybrid.

${ }^{93}$ U.S. CONST. arts. I-III; 5 U.S.C. § 706(2)(C) (empowering reviewing courts to hold agencies accountable by invalidating actions that are in excess of statutory authority).

${ }^{94}$ See, e.g., Cass R. Sunstein, The Office of Information and Regulatory Affairs: Myths and Realities, 126 HARV. L. REV. 1838 (2013); Lisa Heinzerling, Statutory Interpretation in the Era of OIRA, 33 FORDHAM URB. L.J. 1097 (2006).

${ }_{95}$ Climate change adaptation is a prominent example. See, e.g., Exec. Order No. 13514, 74 Fed. Reg. 52,117, 52,124 (Oct. 5, 2009); and Exec. Order No. 13653, 78 Fed. Reg. 66,819, 66,823 (Nov. 1, 2013) (directing agencies to participate in task force to coordinate action on climate preparedness and resilience.). See also Camacho \& Glicksman, supra note 5; Jody Freeman \& Jim Rossi, Agency Coordination in Shared Regulatory Space, 125 HARV. L. REV. 1131 (2012).

${ }^{96}$ For a sampling of this literature, see the sources cited in Camacho \& Glicksman, supra note 5, at 21 n.6.

${ }^{97}$ See infra Part III.
} 
stakeholders. $^{98}$ The value in assessing alternative regulatory design options, not only to acknowledge the reality, but also to assess both the promise and perils of different variations of hybrid governance, is difficult to overstate. In part this is because of the recognition that government cannot "solve" problems on its own and that a well-designed "pluralistic regulatory landscape" improves chances for success. 99 As Professor Magali Delmas has noted, "the inadequacy of governments to resolve some environmental issues has generated the search for alternative governance mechanisms."

Considerable work engaging the appropriate shape of this pluralistic regulatory landscape has been done, such as contributions to the "new governance" literature. ${ }^{101}$ But as Professor Delmas points out, a great deal of additional work is needed: "the research on environmental governance without government, or between government and other actors, is only just emerging."102 Contextualized treatment of this pluralistic landscape is in our view likely to be of especial importance and practical value. ${ }^{103}$ To illustrate its value, we offer such contextualized treatment of one example of hybrid governance, the use of agency gatekeeping to rationalize public and private enforcement litigation, a topic considered recently by Professor Engstrom.

EPA already has significant gatekeeping authority, as Professor Engstrom notes. ${ }^{104} \mathrm{We}$ consider here how EPA's exercise of this authority might influence the capacities of public and private enforcers and affect environmental regulatory enforcement and compliance. All other things being equal, EPA would seemingly want to exercise its gatekeeping power lightly in order to encourage private enforcement litigation in circumstances in which other strategies for inducing compliance, such as reliance on positive incentives, do not yield desired results. Indeed, in addition to exercising its gatekeeping responsibilities with a light touch, EPA might want to engage private enforcers affirmatively to encourage invigorated private enforcement efforts. Similarly, an agency posture of weak gatekeeping might be desirable where obstacles (such as limited government enforcement resources) exist to traditional government deterrence-based enforcement. ${ }^{105}$ In other words, an agency may opt for relatively weak gatekeeping when limited government capacity exists.

\footnotetext{
${ }^{98}$ See, e.g., Hari M. Osofsky \& Hannah J. Wiseman, Hybrid Energy Governance, 2014 ILL. L. REV. 1 (defining hybrid governance to include multiple levels of government and private entities). See also Grabosky, supra note 81, at 118 (suggesting that technology advances may engender "wiki-regulation"); THE TOOLS OF GOVERNMENT: A Guide to THE New Governance (Lester M. Salamon ed., Oxford Univ. Press 2002) [hereinafter Tools Of Government]; Jody Freeman, The Private Role in Public Governance, 75 N.Y.U. L. REV. 543 (2000).

${ }^{99}$ Engstrom, supra note 3, at 629.

${ }^{100}$ Id. at 629 .

${ }^{101}$ See supra note 9 (citing examples of new governance literature).

102 GOVERNANCE FOR THE ENVIRONMENT, supra note 3, at 223.

${ }^{103}$ Engstrom refers to the "complex ecologies of enforcement" within which multiple public and private enforcers operate and with which they interact. Engstrom, supra note 3, at 623; see also id. at 662 (arguing that "an ideal gatekeeper agency focused on optimal deterrence will join and leverage the enforcement efforts of overmatched private enforcers who will not otherwise fully vindicate the public interest"). For another recent example of analysis of regulatory design of public enforcement mechanisms, see Margaret H. Lemos \& Max Minzner, For-Profit Public Enforcement, 127 HARV. L. REV. 853 (2014).

${ }^{104}$ See also infra notes 110, 211 and accompanying text (describing diligent prosecution bar).

${ }^{105}$ On the other hand, attention to other components of the regulatory process, such as clarity and verifiability, might be even more effective, as the Colorado hazardous waste example referred to above reflects. See supra note 15. Our purpose in this section is to consider EPA's use of its existing gatekeeping authority, not to propose reforms in the scope or nature of that authority. Several experts on workers' health and safety laws have urged the creation of a
} 
Conversely, EPA may want to exercise its gatekeeping authority aggressively if it is concerned that expansive private enforcement will undermine national consistency in approaching compliance challenges. ${ }^{106}$ For example, private enforcement efforts that focus on securing particular types of relief with which an agency has concerns, in lieu of the types of relief it favors, may influence the desirability of a significant private enforcement presence ${ }^{107}$ because of both legislative fidelity and coordination issues, to use Professor Engstrom's terms. ${ }^{108}$

Professor Engstrom's focus on agency gatekeeping as a mechanism to take advantage of the hybrid character of enforcement litigation gives little attention to another key actor, state agencies. The cooperative federalism structure of the environmental laws, and the central role of the states in enforcement, is an important part of the discussion in attempting to rationalize public and private enforcement of those laws. ${ }^{109}$ Thus, state capacity (in terms of resources and will) in bringing enforcement actions is an important issue in assessing the need for and desirability of EPA's exercise of its gatekeeping authority.

We also think it is important in rationalizing enforcement litigation to be aware that a state, like EPA, can prevent the filing of a citizen suit by commencing and "diligently prosecuting" its own enforcement action after being notified by a prospective citizen suit plaintiff that it intends to file suit against an alleged violator. ${ }^{110}$ Complaints have been made

citizen suit provision analogous to those in many federal pollution statutes to supplement the government's inadequate enforcement initiatives under the Occupational Safety and Health Act of 1970, 29 U.S.C. §§ 651-678, that has resulted, among other things, from a shortage of inspectors. See Martha McCluskey et al., The Next OSHA: Progressive Reforms to Empower Workers, Center for Progressive Reform White Paper 4-5 (July 2012), available at http://www.progressivereform.org/articles/Next_Generation_OSHA_1207.pdf. Others have urged the addition of citizen suit provisions to other statutes, such as those dealing with food labeling, to redress perceived government enforcement shortcomings. See, e.g., James Springer, The Success of the Citizen Suit: Protecting Consumers from Inaccurate Food Labeling by Amending the Federal Food, Drug, and Cosmetic Act, 68 FOOD \& DRUG L.J. 401 (2013).

${ }^{106}$ Cf. Eric Biber \& Berry Brosi, Officious Intermeddlers or Citizen Experts? Petitions and Public Production of Information in Environmental Law, 58 UCLA L. REV. 321, 329-30 (2010) (describing disruptions to the agenda of the Consumer Product Safety Commission resulting from expansive citizen petition mechanism).

107 See, e.g., David S. Mann, Comment, Polluter-Financed Environmentally Beneficial Expenditures: Effective or Improper Abuse of Citizen Suits under the Clean Water Act, 21 ENVTL. L. 175, 192-94 (1991) (describing Justice Department efforts to block citizen suit settlements involving expenditures by defendants on environmentally beneficial projects). Cf. Robert D. Snook, Environmental Citizen Suits and Judicial Interpretation: First Time Tragedy, Second Time Farce, 20 W. NEw ENG. L. REV. 311, 328 (1998) (noting tendency of some to "look hard for reasons to block citizen suits that are perceived as infringing on government prerogatives or wasting government assets").

${ }^{108}$ Engstrom identifies three critiques of private enforcement - zealousness, legislative fidelity, and coordination. In his view, coordination problems stemming from a mixed public-private enforcement regime include wasteful duplication of effort and a lack of coherence that disrupts cooperative relationships between regulators and regulatory targets. Engstrom, supra note 3, at 634-37. This issue has arisen in the context of supplemental environmental projects, among others. See David L. Markell, Is There a Possible Role for Regulatory Enforcement in the Effort to Value, Protect, and Restore Ecosystem Services?, 22 J. OF ENVTL.\& LAND USE L. 549 (2007).

${ }^{109}$ States are typically the primary enforcers under federal pollution statutes such as the CWA, as indicated below. See infra Part IIA. Our comment in the text that Professor Engstrom gives little attention to state enforcement is not meant as a criticism, but instead simply highlights the wider lens of analysis we sought to bring to this project compared to Professor Engstrom's effective and thoughtful effort to focus more narrowly on the agency gatekeeping mechanism for influencing private enforcement litigation.

${ }^{110}$ See, e.g., 33 U.S.C. § 1365(b)(1)(B); 42 U.S.C. § 6972(b)(1)(B); 42 U.S.C. § 7603(b)(1)(B). To this extent, the federal pollution laws already include a gatekeeping mechanism. 
over the years that some states have reacted to citizen suit notices by commencing an enforcement action against the putative civil suit defendant and then settling the action on terms favorable to the regulated entity because that entity was important to the state's economy or had valuable political connections. ${ }^{111}$ EPA has the authority, and responsibility, to exercise a different type of gatekeeping authority when it learns of state action that may undermine effective enforcement - here, the federal gatekeeping authority involves EPA's authority to withdraw a state's authorization. ${ }^{112}$ Effective enforcement to address significant violations under the environmental laws is a three-legged stool, with each leg (federal, state, and private enforcement) having multiple pieces. EPA actually has at least two types of gatekeeping authority available to rationalize the use of enforcement tools given the multiple actors involved.

While we have devoted a few pages to the particular context of agency gatekeeping of private enforcement litigation in an effort to illustrate the importance of considering the hybrid character of enforcement and compliance contextually, a final point about the hybrid character of this realm is that the range of actors involved in such governance obviously extends far beyond agency and private enforcers. Similarly, the opportunities for hybrid governance to promote effective compliance and enforcement extend far beyond the realm of ex post enforcement litigation. ${ }^{113}$ A critical observation about this central feature of contemporary governance is that efforts to enhance compliance should take into account how best to engage all stakeholders throughout the entire regulatory process. ${ }^{114}$

\footnotetext{
${ }^{111}$ See, e.g., Andreen, Motivating Enforcement, supra note 48, at 85 ("While one might think that this notice provision would often shame the government into taking tough action, it has often been used, in a rather perverse fashion, 'to blunt more vigorous citizen enforcement efforts."'); Trip Gabriel, Michael Wines \& Cotal Davenport, Chemical Spill Muddies Picture n a State Wary of Regulations, N.Y. TIMES, Jan. 19, 2014 (quoting attorney for environmental NGO, who claimed that "[ $\mathrm{t}$ ]he state stepped in with sweetheart deals every time we threatened to sue" facility in West Virginia responsible for chemical spill); Regulatory Favoritism in North Carolina, N.Y. TIMES, Feb. 17, 2014 (referring to the "tawdry tale" of maneuvering by state regulators to block citizen suits against politically powerful utility company); Trip Gabriel, Ash Spill Shows How Watchdog Was Defanged, N.Y. TIMES, Mar. 1, 2014 (quoting attorney for environmental NGO who complained that North Carolina filed an enforcement action that precluded a CWA citizen suit and then entered "a behind-closed-doors settlement" requiring no cleanup). ${ }^{112}$ Hammond \& Markell, supra note 5.

${ }^{113}$ According to Delmas, "the inadequacy of governments to resolve some environmental issues has generated the search for alternative governance mechanisms." GOVERNANCE FOR THE ENVIRONMENT, supra note 3, at 223. There are enormous varieties of governance, including self-regulation in the form of Responsible Care, see American Chemistry Council, Responsible Care, http://responsiblecare.americanchemistry.com/?gclid=CN6klbiLkroCFQg4AodLVQAIQ, supply chain influences, and certification schemes. See ISO 14001: ENVIRONMENTAL MAnAgEment Systems (2004); John C. Cruden, The Brave New World of Private Governance, 30 ENVTL. F. 60, 60 (2013) (discussing private certification standards for private forests); Lesley K. McAllister, Regulation by ThirdParty Verification, 53 B.C. L. REV. 1, 14 (2012). Regulatory instruments may entail elements of state, selfregulatory, and third-party activity. Grabosky, supra note 81, at 120.

${ }^{114}$ It is worthwhile to consider the roles that NGOs of all stripes play today in each of our five components of effective regulation. See Esworthy, How Are They Enforced?, supra note 59, at 1 (listing federal, state, tribal, and local governments, regulated parties, courts, interest groups, and the general public as relevant stakeholders). For discussion of the roles of NGOs during different parts of the regulatory process, see, e.g., Wendy Wagner, Katherine Barnes \& Lisa Peters, Rulemaking in the Shade: An Empirical Study of EPA's Toxic Air Emission Standards, 63 ADMIN. L. REV. 99, 151 (2011) (suggesting that the predominance of certain stakeholders may skew the regulatory process in unanticipated ways that frustrate regulatory goals, and concluding that "at least some publicly important rules that emerge from the regulatory state may be influenced heavily by regulated parties, with little to no counterpressure from the public interest”); Esworthy, How Are They Enforced?, supra note 59, at 14. See also EPAOECA, Report on Environmental Violation, http://www.epa.gov/tips (discussing an initiative, entitled the "National
} 


\section{2. "Reality Checks" as a Contextual Design Issue}

A second type of contextual issue relevant to the design of regulatory enforcement structures is what we term the "reality check" feature. In assessing or revisiting regulatory design, it is critical to assess the agency's (here EPA's) actual performance in conducting enforcement, the challenges the agency has faced, and opportunities to improve performance by altering regulatory features or practices in ways suggested by past experience. As we discuss in more detail in Parts II and III below, EPA has experienced and acknowledged significant shortcomings in its enforcement and compliance program. There are opportunities to improve on this track record with respect to each of the five components of effective regulation identified above, ${ }^{115}$ as well as significant challenges in doing so.

\section{Dynamism}

The degree of dynamism is a third contextual issue relevant to regulatory design. This feature does not receive much attention in some of the regulatory design literature, ${ }^{116}$ but we believe it deserves emphasis. Effective regulatory design requires an understanding of the extent to which key features of regulation are likely to be static or dynamic over time. This feature differs from the reality check feature in that it focuses not on whether existing regulatory practices have worked as anticipated, but on whether the regulatory environment itself has shifted in ways that affect regulatory goals.

Concerns that climate change is causing transformative shifts in the environment are becoming more widespread. Scholars and others are beginning to consider the impacts of such changes on not only the content of regulation, but also on regulatory structure. For example, Professors Robin Craig and J.B. Ruhl recently suggested that the impacts of climate change warrant a fundamental reappraisal of the structure of agency procedures. In particular, they urged more attention be given to adaptive approaches to governance rather than what they consider to be unavoidably limited ex ante approaches:

The idea of adaptive management is that agencies should be free to make more decisions, but that the timing of those decisions is spread out into a continuous process that makes differentiating between the "front end" and the "back end" of decisionmaking much less relevant. Rather than make one grand decision and move on, agencies employing adaptive management engage in a program of iterative decisionmaking following a structured, multistep protocol: (1) definition of the problem, (2) determination of goals and objectives for management, (3) determination of the baseline, (4) development of conceptual models, (5) selection of future actions, (6) implementation and management actions, (7) monitoring, and (8) evaluation and return to step (1). ${ }^{117}$

Report a Violation" website, which was designed to encourage citizens to report potential environmental violations to promote verifiability); Hammond \& Markell, supra note 5 (noting that citizens may file petitions with EPA asserting that a state is not effectively enforcing its environmental laws, prompting EPA to investigate potential shortcomings).

${ }^{115}$ See supra Part IA.

116 See, e.g., Engstrom, supra note 3.

117 Craig \& Ruhl, supra note 12, at 7. 
In addition, changes in agency staffing levels and financial resources, improvements in monitoring technology, and the capacity of regulated parties and NGOs to participate in regulatory implementation are among a litany of factors that affect EPA's capacity for effective governance, especially as it pertains to enforcement and compliance. ${ }^{118}$ EPA should consider these changes in formulating and implementing approaches to achieving desired levels of enforcement and compliance more generally. EPA is already taking steps to do so. For example, to address compliance challenges EPA is increasingly relying heavily on new monitoring tools and data management capabilities. These include infrared cameras that can detect pollution emissions otherwise invisible to the naked eye and electronic reporting such as EPA's Greenhouse Gas Reporting Tool that are intended to save time and money, increase transparency, and ultimately yield improved compliance. ${ }^{119}$

Thus, the contextual reality of dynamism suggests that an indispensable component of regulatory design is awareness of the likelihood that normative objectives may change over time. It is also important to consider the shifting capabilities and interests of different key actors throughout the entire regulatory enterprise and the extent to which these developments should influence design of regulatory structures. ${ }^{120}$

\section{Salience}

A final part of the regulatory design puzzle is the importance of salience. In a world of limited resources, policymakers interested in regulatory design to improve compliance should prioritize changing certain aspects of the regulatory process more than others. ${ }^{121}$ Informed deliberation about possible redesign of agency governance strategies requires attention to the nature and priority of the challenges an agency faces. It also requires consideration of all of the opportunities available to improve performance.

To return to Professor Engstrom's effort to rationalize integration of private enforcers into the public compliance promotion effort, the possibility of and parameters for agency gatekeeping is likely to be a salient issue in many contexts (environmental and otherwise) in the

\footnotetext{
${ }^{118}$ The full array of ways in which the regulatory environment may shift is beyond the scope of this article. A rich literature investigates how regulated parties are motivated by different factors, including utilitarian considerations, cultural norms, and habits. It is worth considering all of these sources of motivation, and how they may shift over time, in regulatory design. See, e.g., GovernANCE FOR THE ENVIRONMENT, supra note 3, at 9, 223; Michael P. Vandenbergh, Amanda P. Carrico \& Lisa Schultz Bressman, Regulation in the Behavioral Era, 95 MinN. L. REV. 715 (2011); Michael P. Vandenbergh, Order Without Social Norms: How Personal Norm Activation Can Protect the Environment, 99 NW. U. L. REV. 1101 (2005); Michael P. Vandenbergh, Beyond Elegance: A Testable Typology of Social Norms in Corporate Environmental Compliance, 22 STAN. ENVTL. L.J. 55 (2003); Neil Gunningham, Robert A. Kagan \& Dorothy Thornton, Social License and Environmental Protection: Why Businesses Go Beyond Compliance, 29 LAW \& SOC. INQUIRY 307 (2004).

119 Giles, supra note 24, at 24-25.

${ }^{120}$ The contextual design challenges we have identified may affect each other. Approaches such as "new governance" approaches are typically dynamic, for example. See, e.g., Grabosky, supra note 81, at __ (suggesting that the increased role of NGOs stems partly from a retreat by government that has created a regulatory vacuum). Grabosky suggests that "regulatory space is contested, and resulting relational interactions between institutions are often complex." Id. at 116. Some, including Engstrom, favor orchestration of different actors, while others "may see a regulatory system characterized by spontaneity as inevitable." Id. at 115-16.

${ }^{121}$ As indicated in Part III, prioritization is an important feature of EPA's ongoing effort to reinvent its CWA enforcement approach. Prioritization based on risk is also an important feature of Canada's effort, especially given increasing demands and limited resources. Auditor General Report, supra note 3, at 9.
} 
effort to improve regulatory compliance. It seems indisputable, at least to us, however, that an agency's first step when confronting an enforcement challenge should not be to automatically focus on any single component of the regulatory scheme, such as the appropriate structure of an agency gatekeeping regime. ${ }^{122}$ This is a well-understood concept: while hammers work well for nails, other tools are better for other circumstances. Before moving forward to address a particular enforcement or compliance challenge, an agency should be sure it considers the five key components of environmental enforcement and compliance outlined in Part IA and the contextual design issues addressed in this section to assess which mix of viable options is likely to prove most effective.

In the Colorado hazardous waste initiative we discuss above, ${ }^{123}$ for example, a state agency made a judgment to prioritize promoting compliance in a particular sector of the regulated community because of features of that community (e.g., high levels of noncompliance, significant aggregate volumes of waste generated). The agency was then able to make significant improvements in its regulatory approach by refining a few of our key components of effective regulation, notably clarity, verifiability, and the mix of sanctions for noncompliance. There was little need to consider rationalization of public and private enforcement litigation as part of this redesign. The Colorado example obviously does not mean that the particular strategies used there to improve clarity and verification and, ultimately, compliance, should be used across the board. Other noncompliance challenges will require different responses to yield desired results. Ultimately, agencies would be well-advised to engage in priority-setting on multiple levels when addressing enforcement and compliance concerns. A first level involves identifying the challenges that most need attention. The second involves identifying the mix of tools that is most likely to be effective. We suggest that both the components of regulation and contextual design issues discussed in this Part offer a starting point for taking this second step in a systematic and thoughtful way. ${ }^{124}$

II. Contextualizing the Conceptual Framework for Effective Regulatory Compliance Design: An Overview of EPA's Compliance Track Record and Challenges

As Part I indicates, informed regulatory design requires an understanding of the entire regulatory process and of the actors who play critical roles throughout that process, whether the goal is the design of a regulatory scheme writ large, or of a particular piece of that scheme such as the enforcement and compliance promotion function. We now turn to a brief review of some of the real-world compliance-related challenges and opportunities EPA faces to illustrate the importance of context in regulatory design. In doing so, we focus on the second and third design challenges introduced in Part IC - the need to consider an agency's experience based on past performance of the regulatory structures being assessed for possible revision and the ways in

\footnotetext{
${ }^{122}$ We are not suggesting that Professor Engstrom would urge that such a first step focus on gatekeeping or any other particular component of the enforcement process. Our discussion in the text is intended to provide a wide lens for considering the value of scholarship that offers a more particularized focus on a single regulatory design mechanism, such as Professor Engstrom's consideration of agency gatekeeping strategies.

123 See supra notes 72-74 and accompanying text.

${ }^{124}$ Others have pointed to the challenges facing agencies in the enforcement and compliance realm. See Esworthy, How Are They Enforced?, supra note 59, at 5 (noting that policymakers must determine "how to balance punishment and deterrence through litigation with compliance assistance, incentive approaches, self-auditing or correction, and voluntary compliance").
} 
which the dynamic nature of the regulatory environment bears on regulatory design, particularly of effective enforcement and compliance structures.

Evaluating effectiveness in inducing compliance is an extraordinarily difficult task. ${ }^{125}$ It is worth being mindful of the old adage about optimists seeing the glass half full and pessimists seeing the same glass as half empty in considering EPA's performance and appraisals of its enforcement efforts. Nevertheless, a wide variety of observers, inside and outside government, have identified significant concerns over EPA efforts to promote compliance. EPA faces substantial barriers in overcoming these challenges, including resource constraints (its own and those of the states), and a changing (in some cases expanding) regulated community. There are, however, some promising signs on the regulatory design horizon as well.

The salient point about the contextual overview we provide in this Part is that extant and upcoming challenges, as well as emerging opportunities, demonstrate that efforts to improve regulatory design should proceed with an understanding of the nature of the challenges an agency has faced and will face and the tools available to meet those challenges. For example, concerns that a regulatory design that enables private enforcement suits will lead to problems with private enforcement such as overzealousness, coordination challenges, or infidelity to legislative objectives are likely to be fairly minor in a context in which there is rampant noncompliance, violations are causing significant environmental degradation and harm to public health, and responsible agencies have proved incapable of or unwilling to enforce against substantial numbers of significant violators. On the other hand, such concerns are likely to be much more relevant when compliance challenges are complex and require sophisticated, integrated strategies, and a responsible agency's efforts to address these challenges efficiently and effectively are likely to be undermined by the presence of a host of other erstwhile enforcers.

\section{A. Agency Enforcement Records}

The Government Accountability Office (GAO), EPA's Office of Inspector General (OIG), EPA's Administrator, and EPA's own enforcement office have all offered highly critical assessments of EPA's performance in promoting compliance with environmental regulatory

\footnotetext{
${ }^{125}$ Esworthy, How Are They Enforced?, supra note 59, at 5, 40 (noting that "how best to measure the success and effectiveness of enforcement" is an issue of continuing interest and that evaluating and measuring the effectiveness of enforcement and compliance activities "can be quite complicated"). EPA acknowledged this reality recently in a draft strategy for improving oversight of state enforcement. U.S. EPA, National Strategy for Improving Oversight of State Enforcement Performance 2-3 (Aug. 27, 2013 draft) [hereinafter EPA, Improving Oversight], available at http://environblog.jenner.com/files/national-strategy-for-improving-oversight-of-state-enforcement-performance.pdf (link provided in Steven M. Siros, EPA Proposes Increased Oversight Of State Enforcement Activities (Oct. 18, 2013), available at http://environblog.jenner.com/corporate environmental_1/2013/10/epa-proposes-increasedoversight-over-state-enforcement-activities.html) (noting complexity of measuring state enforcement and that EPA's data are incomplete in part because its current metrics are based on activities states perform, rather than compliance levels within regulated sectors, which are difficult to determine). There is an extensive measurement literature. The Government Performance and Results Act (GPRA), in its various manifestations, seeks to focus on results and their measurement. See, e.g., Office of Management and Budget, Delivering on the Accountable Government Initiative and Implementing the GPRA Modernization Act of 2010 (April 14, 2001), M-11-17, available at http://www.whitehouse.gov/sites/default/files/omb/memoranda/2011/m11-17.pdf; U.S. Government Accountability Office, Managing for Results: GPRA Modernization Act Implementation Provides Important Opportunities to Address Government Challenges (May 10, 2011, GAO-11-617T), available at http://www.gao.gov/products/GAO11-617T.
} 
requirements. ${ }^{126}$ In a December 2012 report, for example, the GAO noted that "[i]n recent years, EPA has reported that it is not achieving all of the environmental and public health benefits it expected in regulating certain entities because of substantial rates of noncompliance in some programs."127 Compounding the challenge in inducing compliance at desired levels is the enforcers' ignorance of the scope of the problem they are addressing. As the GAO also noted, "because of incomplete or unreliable data on compliance in some programs, such as the [National Pollutant Discharge Elimination System (NPDES) permit program under the CWA], EPA cannot determine the full extent of entities' compliance."128 Scholars also have noted EPA's failure to require regulated entities to submit the kinds of information needed for accurate agency assessment of compliance status. ${ }^{129}$

Concerns about government enforcement extend beyond EPA's performance. An essential feature of many of the key environmental regulatory statutes is their reliance on a cooperative federalism structure. Congress has enacted pollution control laws such as the CAA and CWA, charging EPA with ultimate responsibility for implementing these laws and achieving their goals (through actions that include standard-setting, review of state-issued permits, and concurrent enforcement authority). It has also empowered qualified and interested states, however, to play a significant role in implementation, through planning, permitting, and enforcement, under laws states adopt for that purpose. ${ }^{130}$ It has done so, among other reasons, out of respect for state sovereignty, especially in areas of traditional state concern, ${ }^{131}$ to take advantage of state expertise about local conditions, to support the legitimacy of environmental regulation, and to enhance the total resources available to tackle environmental problems. ${ }^{132}$ Over the years, EPA has authorized increasing numbers of states to take primary responsibility for implementation of the major environmental laws, and the states are regarded as the primary enforcers under the major federal environmental regulatory statutes. ${ }^{133}$ As a result, much of the

\footnotetext{
${ }^{126}$ For a recent collection of some of the reviews, see Esworthy, How Can They Be Enforced?, supra note 59, at 2-4. See infra Part III for additional discussion of concerns about EPA's enforcement record.

${ }^{127}$ U.S. Government Accountability Office, EPA Should Develop a Strategic Plan for Its New Compliance Initiative, GAO-13-115, at 1-2 (Dec. 2012), available at http://www.gao.gov/assets/660/650711.pdf [hereinafter GAO, Strategic Plan].

${ }^{128}$ Id. at $1-2$.

${ }^{129}$ See, e.g., Wendy E. Wagner, Administrative Law, Filter Failure, and Information Capture, 59 DUKE L.J. 1321, 1348-49 (2010) (data inadequacies concerning regulatory requirements for toxic air pollutant emissions).

${ }^{130}$ EPA has the opportunity to play a significant role even if a state is authorized to implement a program. For a description of cooperative federalism under federal environmental statutes, see generally Robert L. Glicksman, From Cooperative to Inoperative Federalism: The Perverse Mutation of Environmental Law and Policy, 41 WAKE FOREST L. REV. 719 (2006). Not all of the federal environmental statutes are built on a cooperative federalism foundation. Statutes such as the Federal Insecticide, Fungicide, and Rodenticide Act, 7 U.S.C. §§ 136-136y, and the Toxic Substances Control Act, 15 U.S.C. §§ 2601-2697, for example, are not.

${ }^{131}$ See, e.g., 33 U.S.C. $\S 1251$ (b) ("It is the policy of the Congress to recognize, preserve, and protect the primary responsibilities and rights of States to prevent, reduce, and eliminate pollution ....”). See also 42 U.S.C. § 7401(a)(3) (concerning air pollution); 42 U.S.C. § 6901(a)(4) (concerning solid waste management). 132 See Erin Ryan, Negotiating Federalism, 52 B.C. L. REV. 1, 90 (2011); William W. Buzbee, State Greenhouse Gas Regulation, Federal Climate Change Legislation, and the Preemption Sword, 1 SAN DiEGo J. Climate \& ENERGY L. 23, 35-37 (2009) ("Empowering state and local governments to play their own supplementary roles in enforcing the law could be the equivalent of additional cops on the beat.").

${ }^{133}$ See McAllister, supra note 113, at 21 ("In many regulatory programs, states have the primary responsibility for enforcement and are overburdened."); RECHTSCHAFFEN \&. MARKELL, supra note 5, at 43 ("Congress established a 'cooperative federalism' structure that makes EPA ultimately responsible for program delivery while reserving the primary front lines implementation role for willing and capable states.").
} 
compliance promotion work is now done by the states with oversight from EPA. According to one account, states conduct about ninety percent of all environmental regulatory inspections and file eighty to ninety percent of environmental enforcement actions. ${ }^{134}$ Moreover, the number of state enforcement actions may dwarf the level of private enforcement, even under a statute such as the CWA in which citizen enforcement historically has been high. ${ }^{135}$ Thus, assessments of the efficacy of state performance are (or to be plausible must be) at the heart of efforts to evaluate government enforcement performance more generally. ${ }^{136}$

The GAO and EPA's OIG, among others, have documented significant deficiencies in states' performance. ${ }^{137}$ Both entities have reported inconsistencies in state environmental enforcement, and the OIG characterized state enforcement programs as "underperforming," notwithstanding EPA's efforts to improve state performance and oversight consistency. ${ }^{138}$

EPA's enforcement office also has acknowledged serious deficiencies in state performance. In an August 2013 draft strategy to improve oversight of state enforcement, EPA noted that its reviews of state performance identified four "unresolved and recurring" significant issues concerning state enforcement (or the integration of federal and state enforcement programs) that require focused attention:

- Widespread and persistent data inaccuracy and incompleteness in national data systems, which make it hard to identify when serious problems exist or to track state actions;

- Routine failure of states to identify and report significant noncompliance;

- Routine failure of states to take timely or appropriate enforcement actions to return violating facilities to compliance, potentially allowing pollution to continue unabated; and

- Failure of states to take appropriate penalty actions, which results in ineffective deterrence for noncompliance and an unlevel playing field for companies that do comply. 139

\footnotetext{
${ }^{134}$ McAllister, supra note 113, at 21. See also Esworthy, How Are They Enforced?, supra note 59, at 11 (“A significant proportion of inspections and enforcement actions are conducted by the states.").

${ }^{135}$ See Andreen, Motivating Enforcement, supra note 48, at 75-76 (reporting that referrals of enforcement cases to state attorneys general significantly outstripped citizen suits filed, even at a time when state enforcement was declining).

${ }^{136}$ See Esworthy, How Can They Be Enforced?, supra note 59, at 3 (noting that given states' substantial role under federal pollution statutes, "state autonomy versus the extent of federal oversight is often at the center of debate with regard to environmental enforcement").

${ }^{137}$ See, e.g., id. at 2 n. 5 (collecting sources); U.S. EPA, Office of Inspector General, EPA Must Improve Oversight of State Enforcement, http://www.epa.gov/oig/reports/202/20111209-12-P-0113.pdf (2011) [hereinafter OIG, Improve Oversight]; Memorandum from Robert Perciasepe and Cynthia Giles to Arthur Elkins, Inspector General, Inspector General's (OIG) December 9, 2011 Evaluation Report, Project No. OPE-FYl0-0022, "EPA Must Improve Oversight of State Enforcement" (March 12, 2012), available at http://www.epa.gov/oig/reports/2012/12-P-0113Agency_Response.pdf; CWAP, supra note 29.

${ }^{138}$ GAO, Strategic Plan, supra note 127, at 1-2.

${ }^{139}$ EPA, National Strategy for Improving Oversight of State Enforcement Performance 4 (Aug. 27, 2013 draft), available at http://environblog.jenner.com/files/national-strategy-for-improving-oversight-of-state-enforcementperformance.pdf. EPA's reviews, conducted under its State Review Framework (SRF), are available at http://www.epa.gov/compliance/state/srf/index.html (2004-2012). See also EPA, Improving Oversight, supra note 124, at 11, 15-16 (identifying limited information and inconsistencies in EPA databases concerning state
} 
The upshot is that, as EPA's OIG has found, "state enforcement programs frequently do not meet national enforcement goals." 140 The OIG found that during fiscal years 2003 to 2009, which was before some of the most significant funding declines described below occurred, "performance was low across the board," with some states performing far below average. ${ }^{141}$ For example, EPA established a national goal that states inspect $100 \%$ of major CAA emitters every two years, but the Inspector General found that only eight states met that goal. As of 2009, EPA set a national goal that states inspect $100 \%$ of CWA major permit holders every two years, but in 2010, only two states met that goal, the national average was only 61\%, and 13 states inspected fewer than $50 \%$ of major facilities. ${ }^{142}$ Similarly, only two states met EPA's target for inspections of hazardous waste generators under RCRA, and states averaged inspections at only $62 \%$ of the targeted number of facilities. ${ }^{143}$ The OIG concluded that EPA had failed to hold its regional offices accountable for ensuring that states adequately enforce environmental laws, and that EPA regions did not consistently intervene to correct state deficiencies. ${ }^{144}$

Given these challenges, as well as growing federal and state budget pressures, it has become increasingly difficult to rely primarily on EPA's traditional approach of inspecting individual entities to increase compliance with the nation's environmental laws and regulations. ${ }^{145}$ EPA recently announced a new initiative-Next Generation Compliance - to improve performance by capitalizing on advances in emissions monitoring and information technology. ${ }^{146}$

\section{B. Declining Resources}

enforcement and noting EPA's difficulties in "accurately and consistently tracking the size of the regulated populations").

${ }_{140}$ OIG, Improve Oversight, supra note 137, at 8.

${ }^{141} I d$. at 8.

${ }^{142}$ Id. at 9.

${ }^{143} \mathrm{Id}$. at 10.

${ }^{144} \mathrm{Id}$. at 11, 15. Some statutes authorize EPA to withdraw authority for state permitting programs not administered in accordance with statutory requirements. See, e.g., 33 U.S.C. § 1342(c)(3) (CWA); 42 U.S.C. § 6926(e) (RCRA). One of the prerequisites for delegation of permitting authority to the states is adequate state authority to carry out the regulatory program, including enforcement requirements. 33 U.S.C. § 1342(b)(7). For discussion of EPA's exercise of that authority, see generally Hammond \& Markell, supra note 5.

Statistics such as the number of enforcement actions brought or the amount of penalty dollars recovered in enforcement actions do not necessarily correlate with either levels of environmental protection achieved or levels of compliance. The need for enforcement action may fall, for example, if earlier steps in the regulatory process have succeeded in making compliance easier and motivating regulated entities to comply. Nevertheless, EPA has acknowledged problems in some states' enforcement records and in EPA regional offices' oversight of these programs. See EPA, Improving Oversight, supra note 125, at 2-3 ('EPA's current metrics [for state enforcement activity] are based on the activities the states perform and not on the level of compliance within regulated sectors, which is difficult to assess with the information currently available.").

${ }^{145}$ GAO, Strategic Plan, supra note 127, at 1-2.

${ }^{146}$ See Giles, supra note 24; infra Parts IIB \& III. The GAO has suggested that EPA develop a "strategic plan to integrate Next Generation Compliance into its enforcement and compliance program." GAO, Strategic Plan, supra note 127, at 8. EPA is in the process of doing so. Id. at 9. 
The adequacy of government resources to promote compliance has been a long-standing concern that seems unlikely to be addressed in the near term. ${ }^{147}$ Most of EPA's annual funding comes from discretionary appropriations. The agency's funds increased sharply in the late 1970s, as EPA began implementing many of the foundational environmental laws adopted earlier that decade. ${ }^{148}$ Funding dipped in the early 1980s and then leveled off until late in that decade, after which it increased fairly regularly until fiscal year $2005 .{ }^{149}$ The enacted budget for the agency fell slightly for fiscal years 2006 through 2009, bringing appropriations approximately back to the amounts provided by Congress during the late 1990s. ${ }^{150}$ Adjusted for inflation, EPA's funding in fiscal year 2009 was slightly lower than it was in fiscal year 1978, according to the CRS. ${ }^{151}$ After reaching a peak of $\$ 10.3$ billion in fiscal year 2010, the agency's budget declined to about $\$ 8.5$ billion in fiscal years 2011 and 2012, and a little less in fiscal year 2013..$^{152}$

Further cuts, perhaps significant ones, seem almost inevitable, at least in the near term. ${ }^{153}$ Environmental group spokespersons have characterized budget cuts for EPA as an indirect way to weaken environmental regulations, likening the situation to "death by a thousand cuts.",154 These cuts are likely to affect the agency's capacity to fulfill its responsibilities, including its enforcement function. EPA announced in early 2014, for example, that increasing budget pressure and resulting uncertainty had prompted it to reduce its workforce through employee buyouts. ${ }^{155}$ EPA's workforce had already declined between 2004 and 2012 during a period when

\footnotetext{
${ }^{147}$ Barton Thompson noted in 2000 that "the enforcement wings of both federal and state environmental agencies are often woefully understaffed and underfunded." Thompson, supra note 23, at 191.

${ }^{148}$ EPA's budget increased from $\$ 770$ million dollars in fiscal year 1976 to $\$ 2.7$ billion in fiscal year 1977 to $\$ 5.4$ billion in both fiscal years 1978 and 1979. U.S. EPA, EPA's Budget and Spending, http://www2.epa.gov/planandbudget/budget [hereinafter EPA, Budget]. of 2009, Pub. L. No. 111-5, 123 Stat. 115. Esworthy et al., Appropriations, supra note 151, at 2, 39, 41. EPA's budget declined by 18\% from FY 2010 to FY2012, not counting the additional cuts caused by the sequestration in 2013. Coral Davenport, EPA Funding Reductions Have Kneecapped Environmental Enforcement, NAT'L J., Mar. 3, 2013.

${ }^{153}$ See, e.g., Jean Chemnick \& Jason Plautz, Agency takes \$300M hit in Obama proposal that cuts budget for $5^{\text {th }}$ consecutive year, E\&ENEWS, Mar. 4, 2014. Some past and proposed future cuts seem linked to hostility to EPA's overall mission. A 2013 House Appropriations Committee press release, for example, explained that legislation proposing further budget cuts "reflects significant efforts to rein in the EPA - an agency that has been rife with governmental overreach, overspending on ineffective and unnecessary programs, and costly and questionable regulations." Id. See also Interior Appropriations Bill Limits EPA, Conservation Spending, Farm Futures (July 24, 2013), http://farmfutures.com/story-interior-appropriations-bill-limits-epa-conservation-spending-0-100631-spx_1 (quoting House Appropriations Chairman Hal Rogers) ("In addition, by holding back overly zealous and unnecessary environmental regulations, this bill can have a positive effect on our economy and will help encourage job growth.").

${ }^{154}$ Phil Taylor \& Jason Plautz, House proposed 'devastating' cuts to Interior, EPA accounts in fiscal 2014, ENV'T \& ENERGY DAILY, May 22, 2013 (quoting Frank O'Donnell of Clean Air Watch).

${ }^{155}$ See Emily Yehle, EPA: Strapped agency prepared hundreds of buyouts in sweeping workforce overhaul, E\&E NEwS, Jan. 30, 2014, available at http://www.eenews.net/greenwire/stories/1059993758 [hereinafter Yehle, Strapped].
} 
the overall number of federal employees grew by 14 percent. ${ }^{156}$ Among other things, according to a spokesperson for a government employees' union, the buyouts will result in a reduction in the number of enforcement official available to do inspections. ${ }^{157}$

The impact of a drop in real funding over the years has been magnified by the increase in EPA's regulatory responsibilities resulting from the enactment of new statutory programs (such as the Comprehensive Environmental Response, Compensation, and Liability Act in $1980^{158}$ and the Emergency Planning and Community Right-to-Know Act in $1986^{159}$ ) and the expansion of regulatory programs - often in ways that drew many new sources within the scope of those programs - through amendments to RCRA in $1984,{ }^{160}$ the CWA in $1987,{ }^{161}$ and the CAA in 1990. $^{162}$

The combination of EPA's declining resource pool and increased responsibilities has presented the agency with difficult choices, some of which may impair EPA's enforcement capacity. ${ }^{163}$ In late 2013, EPA issued a Draft Strategic Plan for fiscal years 2014 to $2018{ }^{164}$ In the portion of the Plan devoted to the goal of protecting health and the environment by enforcing laws and assuring compliance, EPA trumpeted its commitment to a "new enforcement paradigm" under its Next Generation Compliance Initiative. ${ }^{165}$ EPA predicted that this Initiative would

${ }^{156}$ EPA's permanent career employees fell by 1.1\% during this period. See U.S. Government Accountability Office, Federal Workforce: Recent Trends in Federal Civilian Employment and Compensation 14, GAO-14-215 (Jan. 2014); Emily Yehle, EPA, Interior lost employees even as governmentwide numbers grew, E\&E NEWS, Jan. 29, 2014. EPA's peak workforce occurred in fiscal year 1999 and had declined by $5.5 \%$ by fiscal year 2012 . See Esworthy et al,, Appropriations, supra note 151, at 20 (noting general downward trend in FTEs since FY 2001); EPA, Budget, supra note 147. For graphic depictions of EPA's budget and full-time equivalent staffing levels over time, see U.S. EPA FY 2014 Budget in Brief, at 13, available at http://www.radonleaders.org/sites/default/files/EPA_FY_2014.pdf.

The size of the workforce as a whole does not necessarily tell the complete story. The GAO has criticized EPA for struggling "to identify its human resource needs and to deploy its staff throughout the agency in a manner that would do the most good." U.S. Government Accountability Office, Environmental Protection Agency, Management Challenges and Budget Observations, GAO-12-149T, at 3 (2011). See also EPA Office of Inspector General, EPA Needs Better Agency-Wide Controls over Staff Resources, Report No. 11-P-0136 (Feb. 22, 2011), available at http://www.epa.gov/oig/reports/2011/20110222-11-P-0136.pdf; EPA Office of Inspector General, EPA Needs Workload Data to Better Justify Future Workforce Levels, Report No. 11-P-0639 (Sept. 14, 2011), available at http://www.epa.gov/oig/reports/2011/201110914-11-P-0630.pdf.

${ }^{157}$ Yehle, Strapped, supra note 155.

${ }^{158}$ Pub. L. No. 96-510, 94 Stat. 2767 (1980).

159 Pub. L. No. 99-499, 100 Stat. 1729 (1986).

${ }^{160}$ Pub. L. No. 98-616, 98 Stat. 3224 (1984).

${ }^{161}$ Pub. L. No. 100-4, 101 Stat. 60 (1987).

162 Pub. L. No. 101-549, 104 Stat. 2468 (1990).

${ }^{163}$ See EPA's Office of Enforcement and Compliance Assurance-Areas of Proposed Budget Adjustment for FY13 (available through a link in Joel Mintz, Cutting EPA's Enforcement Budget: What It Might Mean (Apr. 12, 2012), http://www.progressivereform.org/CPRBlog.cfm?idBlog=A6A2E941-98B3-8007-9CEEB42458BED78E). This source indicates that EPA's Office of Enforcement Compliance and Assurance (OECA) responded to the fiscal year 2013 budget by proposing "disinvestment" in areas such as acid rain control and reduced enforcement of regulatory programs.

${ }^{164}$ Draft FY 2014-2018 EPA Strategic Plan; Availability, 78 Fed. Reg. 69412 (Nov. 19, 2013); Draft FY $2014-$ 2018 EPA Strategic Plan (Nov. 19, 2013), available at http://progressivereform.org/articles/EPA_Draft_Strategic_Plan112013.pdf.

${ }_{165}$ Draft FY 2014-2018 EPA Strategic Plan, supra note 164, at 42. The Initiative is described further at supra notes 2, 145 and accompanying text, and infra Part III. 
enhance enforcement and compliance by relying on innovative enforcement approaches that use new monitoring and reporting technologies. ${ }^{166}$ News reports, however, focused on the portions of the draft Plan indicating that EPA would cut federal inspections by one-third and reduce the number of civil cases filed each year by 23 percent. $^{167}$ EPA insisted that its decision to focus on the biggest violators and to implement real-time monitoring of emissions to prevent violations would enhance compliance. ${ }^{168}$ The shift in enforcement strategy appeared to have been induced at least in part, however, by budgetary pressures, as reflected in the concession by a top EPA enforcement official that "[o]bviously, necessarily with budget cuts, we have to make tough choices." 169

The decline in resources available to the federal government for environmental protection programs generally, and for enforcement functions specifically, is likely to have ripple effects on the robustness of state programs. ${ }^{170}$ The federal government has long provided financial assistance in the form of grants and loans to assist the states in performing their roles under the federal environmental statutes. Between fiscal years 2004 and 2012, annual appropriations for EPA categorical grants to assist states in implementing air, water, pesticide, and hazardous substance programs shrunk by about $\$ 85$ million. ${ }^{171}$ The Environmental Council of the States (ECOS) has expressed concern about reductions in federal funding for state environmental programs. ${ }^{172}$ Some within the federal government apparently share these concerns. ${ }^{173}$

${ }^{166}$ Draft FY 2014-2018 EPA Strategic Plan, supra note 164, at 42.

${ }^{167}$ Neela Bannerjee, EPA plans to sharply reduce inspections, L.A. TIMES, De. 10 2013, available at http://articles.latimes.com/2013/dec/10/business/la-fi-epa-enforcement-20131211. The number of inspections conducted and enforcement actions initiated had already fallen in fiscal year 2013. See EPA, Office of Enforcement and Compliance Assurance, Fiscal Year 2013 EPA Enforcement and Compliance Annual Results 5-6 (2013), available at http://www2.epa.gov/sites/production/files/2014-02/documents/fy-2013-enforcement-annual-resultscharts-2-6-14_0.pdf\#page=5. These numbers provoked an environmental group spokesperson to remark: "They're not doing more with less, they're doing less with less." EPA Urged to Overhaul Enforcement Strategy After FY13 Results Decrease, Inside EPA ENVTL. POLICY AleRT, Feb. 19, 2014, at 32.

${ }^{168}$ See Bannerjee, supra note 167; Emily Yehle, Agency plans to drastically scale back enforcement, E\&E NEWS, Dec. 9, 2013, available at http://www.eenews.net/greenwire/stories/1059991523 [hereinafter Yehles, Scale back] (referring to EPA's intent to focus on work "that makes the biggest difference"). See also Anthony Adragna, Enforcement Cuts, Lack of Detail on Climate Lead Concerns About EPA Strategic Plan, 45 ENV'T REP. (BNA) 110 (Jan. 8. 2014) (reporting claim that the Next Generation Compliance Program would create a more efficient and targeted enforcement program); Jessica Coomes, EPA Enforcement Cases Drop 20 Percent After Decision to Prioritize 'Larger' Cases, 45 ENV'T REP. (BNA) 452 (Feb. 7 2014) (reporting EPA's intent “to pursue larger, more complex, risk-based enforcement cases leading to significant environmental and health gains").

${ }^{169}$ Yehle, Scale back, supra note 168.

${ }^{170}$ See, e.g., Will Reisinger, Trent A. Dougherty \& Nolan Moser, Environmental Enforcement and the Limits of Cooperative Federalism: Will Courts Allow Citizen Suits to Pick up the Slack?, 20 DuKE EnVTL. L. \& POL'Y F. 1, 21 (2010) ("The cooperative model also makes the enforcement of national environmental objectives subject to budget cuts and shortfalls in each individual state, which further threatens the effectiveness of cooperative federalism.").

${ }^{171}$ U.S. Government Accountability Office, Funding for 10 States' Programs Supported by Environmental Protection Agency Categorical Grants, GAO-13-504R, at 1 (May 6, 2013), http://www.gao.gov/products/gao-13$504 \mathrm{r}$ [hereinafter GAO, Funding for 10]. Appropriations for all EPA categorical grants decreased from a \$1.17 billion in fiscal year 2004 to $\$ 1.09$ billion in fiscal year 2012. Id. at 4. For a graph plotting the amounts provided during this period, see id. at 5 .

${ }^{172}$ Esworthy, How Are They Enforced?, supra note 59, at 4 (citing ECOS, March 2008 Green Report: State Environmental Expenditures 2005-2008, March 12, 2008, available at http://www.ecos.org/section/states/spending). ${ }^{173}$ Id. at 4 (noting that the "the level of federal funding allocated to state and tribes to support effective enforcement of federal pollution control laws has . . . been a long-standing congressional concern"). It is often difficult to follow 
The reductions in federal financial support for the states were especially problematic given that many states were cutting funds for their own agencies and enforcement programs at the same time. ECOS concluded in 2009 and 2010 that reductions in state budgets for environmental enforcement threatened the viability of state enforcement programs. ${ }^{174}$ Between fiscal years 2011 and 2012, 24 states reduced funding for their environmental agencies, ${ }^{175}$ reflecting "an overall trend of decreasing budgets" for funding for state environmental agencies and, according to ECOS, "jeopardiz[ing] states' ability to implement federally delegated programs and policies."176 The CRS expressed concern about a mismatch between federal support provided and state needs, noting that "[t]he adequacy of federal funds to assist states with these responsibilities has become a more contentious issue over time, as state revenues and spending generally have declined under recent economic conditions." ${ }^{177}$ The GAO similarly noted that "the importance of federal grants has increased, as some states have reduced their funding for certain environmental programs to address decreased state revenues and significant deficits in funding." 178

Some states responded to reduced funding for environmental programs by reducing staff levels and cutting outreach and technical assistance programs that can facilitate compliance. ${ }^{179}$ State environmental officials have reported to the GAO that resource constraints have required them to institute hiring freezes and reduce staff through attrition and layoffs. In addition, these officials reported that funding freezes or declines have affected their capacity to conduct activities such as permitting, inspections, and monitoring, all of which are critical to effective enforcement. $^{180}$

All of this is to say that implementation of environmental enforcement programs does not occur in a static world. Rather, both the responsibilities and capacities of regulators shift over time. Particularly when growing responsibilities, such as those described in the next section, accompany shrinking resources, policymakers engaged in regulatory design should be cognizant of and account for those realities.

the money trail, given that "[d]etailed reporting of federal funding to states and states' funding contributions for pollution control enforcement/compliance activities is not readily available." Id. at 39.

${ }^{174}$ Id. at 4 (citing ECOS, Status of State Environmental Agency Budgets, 2009-2011, August 2010; ECOS, Impacts of Reductions in FY 2010 on State Environmental Agency Budgets, March 2010; ECOS, Funding Environmental Protection: State Budget Shortfalls and Ideas for Mitigating Them (June 2009), http://www.ecos.org/section/publications).

${ }^{175}$ ECOS Green Report - Status of State Environmental Agency Budgets, 2011-2013, at 1 (Sept. 2012), http://dl.dropboxusercontent.com/u/41680992/September\%202012\%20Green\%20Report.pdf. The 24 states with decreasing budgets experienced larger changes than the 25 states with increasing budgets, and the total decline in state environmental agency budgets from FY2011 to FY2012 averaged \$357,015 per state. Id.

${ }^{176}$ Id. at 2, 5.

${ }^{177}$ Esworthy et al., Appropriations, supra note 151, at 1.

${ }^{178}$ GAO, Funding for 10, supra note 172, at 1.

${ }^{179}$ Id. at 4, 9. On the potential value of technical assistance and outreach by regulators, see Carol Foley \& Michael Elliott, Systems Design and the Promotion of Pollution Prevention: Building More Effective Technical Assistance Programs, 29 GA. L. REV. 449 (1995).

${ }^{180}$ GAO, Funding for 10, supra note 171, at 4, 9-10. 


\section{Changes in the Regulated Community and Regulator Responsibilities and} Capacities: The Dynamic Character of Regulation

At the same time as resources available to agencies to enforce environmental laws have diminished, challenges facing enforcement officials have shifted. Among the factors that have made effective enforcement more daunting for some agencies and programs are an increase in the number of regulated entities; increases in regulatory responsibilities and mandates for agencies and regulated entities alike; implementation of programs that depend on making difficult causal connections between regulated activities and environmental harms; a movement in some contexts away from uniform regulatory treatment toward differentiated responsibility, which may arise under market-based approaches to regulation or other deviations from traditional regulatory tools; and a commitment to target significant violations by smaller sources that have not traditionally been the focus of enforcement attention and activity. ${ }^{181}$

For various reasons, contemporary government enforcement officials would face significant challenges in achieving effective enforcement of environmental laws even if the financial resources available for enforcement were not declining. In some instances, the size of the regulated community has grown. ${ }^{182}$ EPA has referred to the "breadth and expanding scope of the National Pollutant Discharge Elimination System (NPDES) regulated universe" as one of the challenges it faces in improving its enforcement performance. ${ }^{183}$ The number of point sources subject to CWA permitting requirements doubled over a recent ten-year period. ${ }^{184} \mathrm{~A}$ recent appellate court decision established, for example, that pesticide applications that allow chemical residues to enter surface water bodies may trigger regulation under that statute. ${ }^{185}$ Stormwater permitting has also increased the size of the regulated community. ${ }^{186}$

The resulting increase in regulated entities may present difficulties for federal and state regulators. ${ }^{187}$ In New York, for example, regulated point sources increased by 63\% between

\footnotetext{
${ }^{181}$ Esworthy et al., Appropriations, supra note 151, at 4 (noting that funding for enforcement "had not kept pace with the increasing number of mandates and regulations, or with inflation").

${ }^{182}$ See, e.g., Bruce Harper, Trust But Verify: Innovation in Compliance Monitoring as a Response to the Privatization of Utilities in Developed Nations, 48 ADMIN. L. REV. 593, 614 (1996) ("An increase in the number of generators alone holds some potential to make environmental enforcement more difficult.”).

${ }^{183}$ CWAP, supra note 29, at 10.

${ }^{184}$ McAllister, supra note 113 at 21-22. For further discussion of the expansion of regulated sources under the Act, see infra notes 222-28 and accompanying text (discussion of EPA's CWAP).

185 See National Cotton Council of Am. v. EPA, 553 F.3d 927 (6 ${ }^{\text {th }}$ Cir. 2009).

186 See, e.g., U.S. EPA, Office of Inspector General, Limited Knowledge of the Universe of Regulated Entities Impedes EPA's Ability to Demonstrate Changes in Regulatory Compliance, Report No. 2005-P-00024, at 7 (Sept. 19, 2005), available at http://www.epa.gov/oig/reports/2005/20050919-2005-P-00024.pdf (identifying 45\% increase in sources requiring CWA stormwater permits between 2001 and 2005). During the same period, the number of manufacturers covered by the Toxic Substances Control Act increased by 61\%. Id. Likewise, discharges from expanding hydraulic fracturing activities may trigger CWA requirements. See Robin Kundis Craig, Hydraulic Fracturing (Fracking), Federalism, and the Water-Energy Nexus, 49 IDAHO L. REV. 241, 249 (2013).

187 See Kara Cook, Note, The Middle Ground of Pesticide Regulation: Why EPA Should Use a Watershed-Based Permitting Scheme in Its New Aquatic Pesticides Rule, 37 ECOLOGY L.Q. 451, 486 (2010) ("There are significant monitoring and enforcement challenges because of the sudden explosion in permitting applicants.").
} 
1999 and 2012. ${ }^{188}$ In some contexts, it may be possible to reduce the burdens of addressing newly expanded categories of regulated sources through the creation of general permits, such as the ones available under the CWA's dredge and fill ${ }^{189}$ and NPDES ${ }^{190}$ permit programs. Indeed, EPA has developed a general permit for pesticide and herbicide applications over surface waters. ${ }^{191}$ General permits undoubtedly reduce the resource commitment a state must make at the permit approval stage, but agencies continue to have ongoing responsibility for monitoring, oversight of reporting, and inspections. ${ }^{192}$ If agencies seek to reduce their administrative burdens by not only switching from source-specific to general permitting, but also by minimizing oversight of sources covered by general permits through reduced inspections or sporadic review of regulated entities' reports, one trade-off will be a decline in verifiability and accountability. ${ }^{193}$

Changes in the nature of regulatory approaches also may complicate agency performance of enforcement and compliance-related functions. For example, EPA has recently shifted its focus in implementing the CWA from enforcement of technology-based effluent limitations applicable to point sources to achieving state water quality standards through the implementation of ambient quality-based effluent limitations. ${ }^{194}$ Water quality standards are often expressed in terms of maximum ambient concentrations of pollutants in a surface water body, but are sometimes couched in narrative terms. Implementation of such a standard requires a state environmental agency to establish a total maximum daily load (TMDL), which is an aggregate amount of pollution that may be discharged into a surface water body without resulting in concentrations of regulated pollutants in excess of those allowed by a state water quality standard. ${ }^{195}$ Establishing enforceable limits, monitoring whether allowed loadings (clearly

\footnotetext{
${ }^{188}$ Environmental Advocates of New York, Turning a Blind Eye to Illegal Pollution: DEC's Failing Record on Enforcing Environmental Laws 8 (Sept. 2013), http://www.eany.org/our-work/reports/turning-blind-eye-illegalpollution-september-2013.

189 33 U.S.C. § 1344(e).

190 See, e.g., 40 C.F.R. § 122.28(a); California Sportfishing Prot. Alliance v. Chico Scrap Metal, Inc., 728 F.3d 868 ( $9^{\text {th }}$ Cir. 2013) (involving California's Industrial Activities Storm Water General Permit). See generally Jeffrey M. Gaba, Generally Illegal: NPDES General Permits Under the Clean Water Act, 31 HARV. ENVTL. L. REV. 409,413 (2007).

${ }^{191}$ See, e.g., Final National Pollutant Discharge Elimination System (NPDES) Pesticide General Permit for Point Source Discharges From the Application of Pesticides, 76 Fed. Reg. 68,750 (Nov. 7, 2011).

${ }^{192}$ See, e.g., 76 Fed. Reg. at 68,775 (listing among Pesticide General Permit requirements the duties of applicators to monitor adverse incidents and document visual monitoring activities). General NPDES permits may regulate one or more discharge categories, provided all sources within a category are subject to the same or similar monitoring requirements. 40 C.F.R. § 122.28(a)(2)(ii)(D).

${ }^{193}$ Efforts to enforce against private landowners, small businesses, or sectors of the business community (such as agriculture) that traditionally have not been enforcement targets also may pose new challenges, such as increased political opposition. Federal efforts to enforce wetlands permitting requirements under the CWA, for example, have generated political opposition and adverse publicity. See, e.g., Felicity Barringer, Wetlands? What Wetlands?, http:/green.blogs.nytimes.com/2011/04/20/wetlands-what-wetlands/?_r=0 (Apr. 20, 2011) (describing Sackett v. EPA, 132 S. Ct. 1367 (2012), a CWA enforcement action to block construction of a single family home on property alleged to contain regulated wetlands, as an example of the view of libertarians and tea party members that EPA is the "embodiment of government run amok").

194 See, e.g., RoBERT L. Glicksman ET AL, EnVIRONMENTAL Protection: LAW AND POLICY 614 (6 $6^{\text {th }}$ ed. Aspen Pub. 2011) (noting increase in the role of water quality standards).

${ }^{195}$ Upper Blackstone Water Pollution Abatement Dist. v. EPA, 690 F.3d 9, 14 n.8 (1 ${ }^{\text {st }}$ Cir. 2012) (quoting 33 U.S.C. $\S 1313(\mathrm{~d})(1)(\mathrm{C}))$ ("A TMDL is a calculation of the maximum quantity of a pollutant that may be added to a water body from all sources without exceeding applicable water quality standards, including 'a margin of safety which takes into account any lack of knowledge concerning the relationship between effluent limitations and water
} 
enforceable or less so) are producing desired environmental results, and adapting to the findings are all resource-intensive enterprises, perhaps especially if the target is a vague narrative standard rather than a numerical target. ${ }^{196}$ Determining whether a point source violated technology-based effluent limits, which are expressed as caps on end-of-pipe discharges, is a relatively simple matter by comparison. Agency efforts to improve water quality by restoring and maintaining ecologically functioning ecosystems will likely create similar ripple effects on enforcement strategies. ${ }^{197}$ Expansion of the CWA permit program to cover stormwater permitting may make regulators' enforcement tasks more difficult because regulation of stormwater discharges often takes the form of best management practices rather than end-of-pipe discharge limits. ${ }^{198}$ It may be harder to track compliance status with mandates that take the form of ongoing operating practices than it is for numerical discharge limits that can be monitored. ${ }^{199}$ As regulatory challenges change, so do enforcement challenges, affecting the implications of available regulatory design options.

Shifting from traditional regulatory techniques such as technology-based limits that apply to classes of regulated sources to market-based strategies that allow individual regulated entities to alter their responsibilities through inter-source transactions is another change in regulatory approach that is likely to create new enforcement challenges. ${ }^{200}$ Such a shift may make it more difficult to ascertain the nature and extent of enforceable duties of individual regulated entities. $^{201}$ Some emissions trading markets have been exploited through the sale of credits for environmental improvements that would have occurred even without regulation, credits for which sellers have already been fully paid either in the same or another market, or credits that

quality"'). The focus on enforcement of TMDLs is largely the result of citizen suits resulting in court decrees requiring the establishment of delinquent TMDLs. This example illustrates the need for policymakers engaged in regulatory design to consider how one aspect of a regulatory program (such as the availability of citizen enforcement) may affect other such aspects (such as the task of regulators to translate TMDLs into source-specific effluent limitations).

${ }^{196}$ The regulatory and non-regulatory enterprise of seeking to bring an impaired water up to a desired state is complex. Cf. Sarah Birkeland, EPA's TMDL Program, 28 ECOLOGY L.Q. 297, 300 (2001) (referring to "the implementation and enforcement challenges faced by the EPA's TMDL program").

197 GLICKSMAN ET AL., supra note 194, at 550 (describing new objectives geared toward restoration and maintenance of functioning ecosystems and toward control of nonpoint source pollution).

198 See. e.g., Decker v. Nw. Envt. Def. Ctr., 133 S. Ct. 1326, 1338 (2013).

199 See Robert L. Fischman \& Jeffrey B. Hyman, The Legal Challenge of Protecting Animal Migrations as Phenomena of Abundance, 28 VA. ENVTL. L.J. 173, 223 (2010) ("BMPs are harder to monitor and enforce than traditional technology-based limitations because the BMPs are more widely dispersed across the landscape.”).

${ }^{200}$ U.S. environmental law has long been criticized for excessive reliance on traditional regulatory techniques such as uniform technology-based standards applicable to source categories. The critics contend that such approaches are inefficient because they fail to recognize differences among sources in the costs of controlling pollution. See, e.g., Bruce Ackerman \& Richard Stewart, Reforming Environmental Law, 37 STAN. L. REV. 1333 (1985). Policymakers have responded by incorporating market-based mechanisms such as tradeable permits into statutes such as the CAA. See, e.g., 42 U.S.C. $§ 7651 b(b)$ (allowing transfers of allowances for regulated utilities to emit sulfur dioxide that contributes to acid rain).

${ }^{201}$ See, e.g., Dennis D. Hirsch, Protecting the Inner Environment: What Privacy Regulation Can Learn from Environmental Law, 41 GA. L. REV. 1, 39 (2006) ("[I]t is easier to keep track of a uniform technology than to police facility-specific pollution reduction strategies. Second generation strategies encourage differentiation. They accordingly offer less in the way of strict accountability and enforceability and open the door to bad-faith attempts to game the system."). 
did not occur at all except on paper. ${ }^{202}$ Colorado noted that the burden on agencies to improve compliance may increase when requirements are tailored rather than consistent across an industry, not only because it will be more difficult for government inspectors to determine compliance, but also because "it may be more difficult to implement a self-certification program where individualized permits determine unique facility-specific compliance requirements.",203

A final development that may increase the difficulty of enforcement is the effort to address significant environmental threats, even from sources that have not traditionally been the focus of agency enforcement attention, and to address sources that are emitting or discharging relatively small amounts, but whose violations may be cumulatively significant. ${ }^{204}$ If enforcement initiatives target smaller sources, enforcers may have to initiate more actions and commit more resources to enforcement just to achieve the same level of environmental improvement through enhanced compliance. ${ }^{205}$ In addition, data relevant to compliance status may not be available to the same extent for small as for larger sources, making it more difficult to enforce against those sources, or at least more expensive as agencies must amass a data base that does not exist or is incomplete. ${ }^{206}$

Changes in regulatory challenges are not entirely in the direction of making government officials' jobs more difficult. There are also opportunities to promote compliance that may facilitate better performance. As Part III below indicates, these include improvements in monitoring capacity and enhancements in the capacity to manage and disseminate data and other information. Improved understanding of the mix of incentives that promote compliance also holds promise for improving the effectiveness of enforcement efforts. ${ }^{207}$

\section{A Brief Conclusion Concerning the Importance of Context to Regulatory Design}

\footnotetext{
202 See Philip Womble \& Martin Doyle, The Geography of Trading Ecosystem Services: A Case Study of Wetland and Stream Compensatory Mitigation Markets, 36 HARV. ENVTL. L. REV. 229, 291-92 (2012). For descriptions of exploitations of environmental regulatory markets, see Richard Toshiyuki Drury et al., Pollution Trading and Environmental Injustice: Los Angeles' Failed Experiment in Air Quality Policy, 9 DUKE ENVTL. L. \& POL'Y F. 231 (1999); Elisabeth Rosenthal \& Andrew W. Lehren, Profits on Carbon Credits Drive Output of a Harmful Gas, N.Y. TIMES, Aug. 8, 2012, http://www.nytimes.com/2012/08/09/world/asia/incentive-to-slow-climate-change-drivesoutput-of-harmful-gases.html?pagewanted=all\&_r=0. See also Nicklas A. Akers, New Tools for Environmental Justice: Articulating a Net Health Effects Challenge to Emissions Trading Markets, 7 HASTINGS W.-N.W. J. ENVTL. L. \& POL'Y 203 (2001).

203 Schieffelin, supra note 15 , at 18.

${ }^{204}$ Cf. U.S. EPA, Office of Inspector General, Limited Knowledge of the Universe of Regulated Entities Impedes EPA's Ability to Demonstrate Changes in Regulatory Compliance, Report No. 2005-P-00024, at 14 (Sept. 19, 2005), available at http://www.epa.gov/oig/reports/2005/20050919-2005-P-00024.pdf [hereinafter OIG, Limited Knowledge] (reporting that, in multiple program areas, "OECA does not know the cumulative effects of pollution from small entities"). The OIG also reported that "some states and EPA regions have argued that RCRA small quantity generator facility inspections represent some of the most environmentally significant activities that regions and States conduct." Id. See also infra Part III.

${ }^{205}$ Cf. Bradley C. Karkkainen, Environmental Lawyering in the Age of Collaboration, 2002 WIS. L. REV. 555, 560 ("The remaining non-compliance cases often involve either smaller targets or more difficult problems of proof, making them costlier and riskier to litigate.").

${ }^{206}$ See, e.g., OIG, Limited Knowledge, supra note 204, at 8 (discussing absence of reliable data on programs such as CAA regulation of minor stationary sources and regulation of small quantity generators under RCRA).

${ }^{207}$ See infra Part III.
} 
Part I seeks to demonstrate that policymakers designing or redesigning programs dealing with regulatory enforcement and compliance promotion should be aware that the programs operate in a multi-faceted context in which each part of the regulatory process may affect the degree to which other parts are capable of achieving the goal of effective regulation. Further, it highlights several contextual issues (such as the hybrid character of contemporary governance) that deserve close attention. This Part has focused on two contextual issues as they apply to EPA in particular. The first is the agency's enforcement performance record and the impact on it of the resource challenges it has faced and continues to face. The second is the dynamic nature of regulation. Even if one were to take a snapshot of the regulatory process and fully assimilate the interactions among the different phases of the regulatory process and actors participating in it, that understanding is of time-limited value. Past experience with a regulatory program can and should provide lessons that shape policymakers' redesign efforts. Just as important, however, is recognition that the regulatory landscape and the role of its participants changes, sometimes in ways that significantly disrupt settled patterns. If policymakers assume a certain level of state and private enforcement in structuring EPA's own enforcement activities, they may find that the aggregate level of enforcement is not what they anticipated or desired if, for example, state funding of enforcement drops significantly. The same might be true if the Supreme Court were to issue a decision sharply restricting standing for environmental NGOs in citizen suits. ${ }^{208}$ The overarching point is that regulatory design needs to be undertaken, and revisited over time, with a sophisticated understanding of the nature of the regulatory landscape that exists in a particular regulatory setting and of the changes in this landscape that are likely to occur over time.

\section{A Review of EPA's Initiative to "Transform" Compliance and Enforcement under the $\underline{\text { Clean Water Act }}^{209}$}

In this Part we provide a case study of an ongoing EPA regulatory redesign effort that EPA has recently undertaken to bolster compliance promotion strategies under the CWA. We examine EPA's approach in the context of the holistic, contextual depiction of the enforcement and compliance promotion function outlined above. In doing so, we are mindful of the view some scholars have taken, which we have considered throughout the article, that rationalizing public and private enforcement is a central challenge in the modern regulatory state. ${ }^{210}$ The absence of this consideration from EPA's reinvention effort, despite EPA's possession of agency gatekeeping authority and the significant level of private enforcer activity, raises important

\footnotetext{
${ }^{208}$ After the Supreme Court decided Lujan v. Defenders of Wildlife, 504 U.S. 555 (1992), Professor Sunstein opined that "[r]ead for all it is worth," the decision invalidates statutes in which Congress uses citizen suits to control "unlawfully inadequate enforcement of the law." Cass Sunstein, What's Standing After Lujan: Of Citizen Suits, "Injuries," and Article III, 93 MicH. L. REv. 163, 168 (1992). Had Sunstein's expansive reading of the case been adopted by the courts after Lujan, one leg of the three-legged enforcement stool (the federal government, the states, and private citizens) would have been severely impaired. This example shows that yet another actor has the potential to affect operation of enforcement programs, including components designed to rationalize public and private enforcement - the federal courts, who act as "gatekeepers" of their own through the application of standing and other justiciability doctrines.

${ }^{209}$ Transform is EPA's word. See, e.g., Memorandum from Administrator Jackson on Improving Water Quality Transparency and Effective Enforcement of Clean Water Act Requirements (July 2, 2009), available at http://www.epa.gov/compliance/data/results/performance/cwa/jackson-ltr-cwa-enf.html.

${ }^{210}$ E.g., Engstrom, supra note 3.
} 
questions for conceptualizing and implementing strategies for enhancing enforcement and compliance promotion. ${ }^{211}$

Over the past few years, EPA has acknowledged that its strategies for promoting compliance with the CWA need improvement. ${ }^{212}$ In a July 2009 Memorandum, EPA Administrator Lisa Jackson told the head of EPA's enforcement program, Cynthia Giles, that "[w]e are ... falling short [in] the effectiveness of our clean water enforcement programs,",213 and "the level of significant non-compliance with permitting requirements is unacceptably high . ..."214 Jackson accordingly directed Giles to develop an action plan to improve enforcement performance.

In October 2009, EPA's Office of Enforcement and Compliance Assistance (OECA) issued the Agency's Clean Water Action Plan. ${ }^{215}$ Echoing the Administrator's concerns, OECA noted that "[V]iolations are ... too widespread, and enforcement too uneven." 216 OECA also emphasized the challenge presented by a substantially increased universe of regulated parties: "[t]he sheer magnitude of the expanding universe of the NPDES program itself, from roughly $100,000 \ldots$. . sources to nearly a million sources . . . presents challenges in how we regulate and enforce the laws. ..."217 EPA noted that the types of sources known to raise concerns has evolved as well: when EPA developed its enforcement policies, it focused primarily on the largest (or major) facilities with individual permits that are in significant noncompliance. But

\footnotetext{
${ }^{211}$ Our intent here is not to criticize EPA's reinvention effort for its failure to address private enforcement, nor to criticize academic work highlighting the potential value of such enforcement in some contexts. EPA's neglect of the topic may stem from its limited ability to control citizen enforcement initiatives or informational and coordination challenges, among other things. See, e.g., Mark Seidenfeld, Empowering Stakeholders: Limits on Collaboration as the Basis for Flexible Regulation, 41 WM. \& MARY L. REV. 411, 412-413, 428-445, 459-466 (1999-2000) (expressing skepticism about government collaboration with private enforcers). The agency may block citizen suits by commencing and diligently prosecuting a civil or criminal action against the target of a potential citizen suit within 60 days of being notified of a private enforcer's intention to initiate suit. 33 U.S.C. § 1365(b)(1).

${ }^{212}$ Concerns pre-dated this latest EPA call for improvements. See Markell, Deterrence-Based Enforcement, supra note 1; RECHTSHAFFEN \& MARKELL, supra note 5. Efforts to enhance compliance have tended to focused on permit requirements for sources discharging pollutants to surface waters. One of EPA's primary strategies is enforcement litigation against parties operating in "significant non-compliance" with permit obligations. See, e.g., EPA Office of Compliance and Enforcement Assurance, EPA's Interim Significant Noncompliance Policy for Clean Water Act Violations Associated with CSOs, SSOs, CAFOs, and Storm Water Point Sources (Oct. 2007), available at http://www.epa.gov/compliance/resources/policies/state/srf/sncpolicy-attach1.pdf.

${ }^{213}$ Memorandum from Administrator Jackson on Improving Water Quality Transparency and Effective Enforcement of Clean Water Act Requirements (July 2, 2009), available at http://www.epa.gov/compliance/data/results/performance/cwa/jackson-ltr-cwa-enf.html. See also CWAP, supra note 29, at 2 ("Unfortunately, data shows us that we are not getting the compliance envisioned by our laws to protect clean water."); id. at 3 ("State enforcement response to serious violations, whether at large or smaller facilities, is not what it should be."). The memo adds that: 1) traditionally EPA has focused on "major" facilities; 2) it has not required states to submit data about smaller facilities; and 3) therefore, EPA does not know the percentage of smaller sources nationally that are in significant compliance. But for the 28 states, 4 territories, and D.C. which have provided some of these data, the rate of significant noncompliance at smaller facilities is around 45 percent, nearly twice the rate for major facilities. The Plan concludes that EPA and states need consistent data to "formulate appropriate strategies for ensuring compliance from these facilities, and to target enforcement resources to the sources most affecting water quality." Id. at 3.

${ }^{214}$ Memorandum from Administrator Jackson, supra note 213.

${ }^{215}$ CWAP, supra note 29.

${ }^{216}$ Id. at Executive Summary.

${ }^{217}$ Id. at 1, 12 (noting that EPA's CWA program has "expanded its regulated universe more than tenfold").
} 
EPA had found a rate of serious noncompliance at about 45 percent of smaller facilities. ${ }^{218}$ EPA had further concluded that "[i]t is likely that these smaller but more numerous sources are of critical concern, especially where there are clusters of permitted facilities around impaired waters." 219 OECA stated that EPA needed to "revamp" enforcement to meet these challenges. ${ }^{220}$

Based on its own assessment, and considerable outreach, ${ }^{221}$ OECA identified "three major themes for action" to improve compliance, noting that its outreach efforts engendered a "surprising coalescence" around these themes. ${ }^{222}$ The three themes, discussed below, are the need to focus on the most significant threats to water quality and public health, to strengthen EPA-state partnerships and improve the performance of each partner, and to improve accountability and transparency.

\section{A. The Need to Focus Enforcement on the Most Significant Threats}

The first theme for action identified in the CWAP is the need to focus enforcement on the "biggest threats to water quality and public health."223 This strategy (or approach to regulatory design) might seem obvious. But as EPA pointed out, an unintended consequence of EPA's traditional focus on the biggest facilities (known in EPA parlance as "majors") was that EPA paid little attention to the "full range of the NPDES regulated universe,"224 including "nonmajor" sources whose discharges caused significant environmental problems. Thus, EPA's first theme seeks to prioritize enforcement-related efforts by ensuring that these efforts focus on the most problematic sources regardless of size, which previously it had not done.

EPA identified a range of "new approaches and new tools" to address its proposed shift in strategy. ${ }^{225}$ For example, it noted the need to improve data management to facilitate

\footnotetext{
${ }^{218} I d$. at 3.

${ }^{219}$ Id. EPA acknowledged in the CWAP that, "[w]ithout complete and accurate data, it is hard to know how critical the noncompliance at smaller facilities is to water quality." Professor Dick Pierce recognized decades ago that "[s]mall firms do not produce disproportionate quantities of social 'goods.' They do produce massively disproportionate quantities of social 'bads." Pierce, supra note 2, at 539. See also id. at 557 (noting that "small firms account for a disproportionate quantity of the social bads that we attempt to reduce through regulation"); id. at 559 ("Small firms also are responsible for a massively disproportionate share of water and air pollution."). Pierce addressed small firms, not necessarily small facilities, but EPA's assessment in the CWAP indicates that similar conclusions may apply to small sources, especially when assessing the aggregate impacts of their discharges.

${ }^{220} \mathrm{CWAP}$, supra note 29, at Executive Summary, 5. EPA noted that some water quality problems are caused by sources not currently being regulated. Id. at 6 . Given our focus on regulatory design, not substantive regulatory content, we do not address the need to revisit the scope of regulatory schemes (such as by covering nonpoint sources currently exempt from most CWA regulation).

${ }^{221}$ Outreach included solicitation of input from academics, industry, and environmental and environmental justice NGOs. Id. at 5.

${ }^{222}$ Id. at 6. EPA has followed through since 2009. See, e.g., Memorandum from Cynthia Giles \& Peter Silva on Interim Guidance to Strengthen Performance in the NPDES Program (June 22, 2010), available at http://www2.epa.gov/enforcement/interim-guidance-strengthen-performance-npdes-program. See also U.S. EPA, OFFICE OF ENFORCEMENT AND COMPLIANCE ASSURANCE, CWA ACTION PLAN IMPLEMENTATION PRIORITIES: CHANGES TO IMPROVE WATER QUALITY, INCREASE COMPLIANCE AND EXPAND TRANSPARENCY (2011) [hereinafter INCREASED COMPLIANCE], available at http://www.epa.gov/compliance/resources/publications/civil/programs/cwa/actionplan-implpriorities.pdf. ${ }^{223}$ CWAP, supra note 29 , at 6 .

${ }^{224} \mathrm{Id}$.

${ }^{225} \mathrm{Id}$. at 7. EPA discussed several new tools in a 2011 memorandum, INCREASED COMPLIANCE, supra note
} 
understanding the relationship between compliance problems and their impacts on water quality. ${ }^{226}$ Data about water quality, permit limits, and permit violations "reside in different systems and have not been routinely used together to help target serious problems."227 EPA also highlighted the importance of improving tools across the spectrum of regulation, indicating that while responses might include enforcement actions, addressing water quality concerns also might require fixing problematic regulations and improving operating permits. ${ }^{228}$ Last, the agency focused on integrating its "state partners" better in its discussion about options for addressing the "biggest threats."229

In short, EPA's strategy in addressing the first significant deficiency it identified in extant compliance promotion efforts involved all four of the contextual design issues we identified above. EPA's goal of better integrating states into its enforcement initiatives reflects the hybrid nature of the regulatory process (our first conceptual design challenge). The agency's decision to refocus its efforts stemmed from the "reality check" provided by past experience (our second contextual design challenge), which showed that historically EPA had paid insufficient attention to significant violators by focusing on a small subset of the regulated party universe. EPA's commitment to take advantage of improved technology to make easily accessible and understandable information available to the public about compliance status, actions EPA and states are taking to address problems, and the effects of those actions on water quality relates to our third contextual design challenge (dynamism). ${ }^{230}$ And, finally, EPA's decision to shift its priorities reflects an agency effort to grapple with our fourth design issue (salience). Further, by focusing on resolving data deficiencies (verifiability) and tools besides formal enforcement (the available mix of rewards and sanctions), EPA considered some of the key components of an effective enforcement and compliance program identified in Part IA; the Agency also recognized the inter-related character of these components, noting, for example, that improved verifiability and better use of sanctions are related.

\section{B. Strengthening the State/EPA Partnership}

The second "major theme for action" that EPA identified in its CWAP, not entirely distinct from the first, is the need to strengthen state performance. In most parts of the country, states are the first line of CWA permitting and enforcement. ${ }^{231}$ The Plan noted that reviews of

\footnotetext{
${ }^{226} I d$. (noting that "[o]nce we have identified significant point source violations across the spectrum of regulated facilities that adversely affect water quality, we will work with state programs to commence appropriate federal and state civil and criminal enforcement actions"). 
state performance identified widespread deficiencies, and EPA noted the importance of federal oversight to motivate improvements in such performance:

[The many reviews of state permitting and enforcement performance] have identified a lack of consistency in performance across states and highlighted common issues such as permit backlogs, failure to identify significant noncompliance, or to take timely and appropriate enforcement. EPA must consistently respond to these issues and press states and ourselves to make the appropriate improvements in order to achieve equitable protection to the public, a level playing field for competing businesses, and fairness across states in how our environmental laws are enforced. ${ }^{232}$

EPA's goal of better integration of federal and state enforcement involves the first of our contextual design challenges - the idea that design efforts should take into account the role of different stakeholders in a hybrid regulatory process. Particularly in the cooperative federalism context built into the environmental statutes, it is unsurprising that EPA would make rationalization of its relationship with the states a top priority. ${ }^{233}$ EPA enforcement leaders over the past couple of decades have highlighted the importance of the state-federal partnership in effective enforcement and compliance promotion. ${ }^{234}$

EPA's focus in the CWAP on rationalizing federal and state enforcement efforts reflects more than just our point about the importance of hybrid governance considerations to regulatory design. EPA's concerns extend to several of the key elements of effective enforcement and compliance promotion we discuss above, including verifiability and the appropriate mix of rewards and sanctions. The fact that EPA decided to so directly and publicly level its criticisms of state performance implicates legitimacy concerns, another important element of effective regulation. EPA's decision to pursue improved enforcement in light of unacceptable past performance reflects the importance of the "contextual design" issue of structuring future efforts in light of assessments of past performance. The agency's apparent decision to regard rationalization of federal and state enforcement as a higher priority than the rationalization of public and private enforcement implicates another of our contextual design issues (salience). ${ }^{235}$

\footnotetext{
${ }^{232}$ Id. These concerns are not new. One observer rendered this assessment 20 years ago: "Enforcement of environmental laws by the EPA and the authorized states, however, has largely been an uncoordinated, piecemeal effort. Individual EPA offices and their state counterparts have generally functioned independently. . . . The insularity of the EPA's separate offices and their state-level counterparts has at times resulted in duplicate and conflicting actions." Peter J. Fontaine, EPA's Multimideia Enforcement Strategy: The Struggle to Close the Environmental Compliance Circle, 18 Colum. J. EnVTL. L. 31, 34 (1993). For book-length treatment, see RECHTSHAFFEN \& MARKELL, supra note 5. See also Markell, Slack, supra note 47, at 8-10. For a recent review of an innovative process intended to empower citizens to raise such concerns administratively, see Hammond \& Markell, supra note 5.

${ }^{233}$ See, e.g., Hari Osofsky, Diagonal Federalism and Climate Change Implications for the Obama Administration, 62 ALA. L. REV. 237, 285 (2011) (discussing cooperative federalism's potential to “create coordinated multiscalar action in which each actor provides its unique contribution"); Robert L. Fischman, Cooperative Federalism and Natural Resources Law, 14 N.Y.U. ENVTL. L.J. 179, 195 (2005) (referring to coordination between federal and state entities as "an irreducible aspect" of cooperative federalism).

234 RECHTSHAFFEN \& MARKELL, supra note 5.

${ }^{235}$ It is not clear from the CWAP whether EPA actually considered the role of private enforcement at all in this particular redesign effort. The Plan makes no reference to the appropriate role of private enforcers or to how they impact public enforcement or desired levels of compliance.
} 
Thus, EPA's goal of strengthening state performance bears on several elements of our conceptual framework for improving regulatory design.

\section{Improving Accountability and Transparency}

The third theme around which EPA and its stakeholders coalesced in the CWAP is the need to improve accountability and transparency. ${ }^{236}$ As it did in identifying the Plan's first two themes, EPA acknowledged that it "lacks nationally consistent and complete information on the facilities, permits, pollutant discharges and compliance status of most NPDES-regulated facilities." 237 Data problems exist across the board, including "data quality, accuracy, and completeness."238 Inevitably, the infrastructure problem these data gaps represent "affects the ability of EPA and states to identify violations . . . , connect violations to water quality impacts, and to share information with the public."239 The Plan notes that the "breadth and expanding scope of the NPDES regulated universe" heightens the challenge of responding to the longstanding data problems. ${ }^{240}$ The CWAP indicates that, because of the size of the challenge and the costs involved (it would cost over $\$ 100$ million/year to generate the data EPA would like to have), EPA will explore new ways to fill these data gaps, including using technological advances. $^{241}$

Innovative information-gathering technologies may facilitate the ability of regulators and potential private enforcers to identify regulatory violations. Geographic information systems, global positioning satellite technologies, and remote sensing devices already support the investigation and enforcement of environmental laws in ways that were not previously possible. ${ }^{242}$ Some of this technology is available to the public at little or no cost from federal or state agencies. $^{243}$ These technologies produce data that are more finely grained than cruder,

${ }^{236}$ Thus, this theme relates directly to the third and fifth components of effective regulation described in Part IA, verifiability and legitimacy.

${ }^{237}$ CWAP, supra note 29, at 10.

${ }^{238} \mathrm{Id}$.

${ }^{239} \mathrm{Id}$.

${ }^{240} \mathrm{Id}$.

${ }^{241}$ See 78 Fed. Reg. 76,005 (July 30, 2013) (proposed rulemaking to require electronic reporting to address quality, accuracy, completeness, and timeliness concerns associated with its data). See Christian Latham, Digitizing Environmental Protrection, REGBLOG (Dec. 5, 2013), available at http://www.regblog.org/2013/12/05-lathamdigitizing-environmental-protection.html (discussing the capacity of the proposed rule to enhance enforcement under the CWA against smaller facilities such as stormwater dischargers).

${ }^{242}$ See Peter Stokely, Using Aerial Photography, Geospatial Data, and GIS to Support the Enforcement of Environmental Statutes, 28-Summer NAT. RESOURCES \& ENV'T 38 (2013). Remote sensing is "the science and art of obtaining information about an object, area, or phenomenon through the analysis of data acquired by a device not in contact with the object, area, or phenomenon under investigation.” Kenneth J. Markowitz, Legal Challenges and Market Rewards to the Use and Acceptance of Remote Sensing and Digital Information as Evidence, 12 DUKE ENVTL. L. \& POL'Y F. 219, 221 (2002). According to Dave Owen, "increased data availability, new software systems, and exponentially greater computer power have combined to turn spatial analysis - that is quantitative analysis of data coded to specific geographic coordinates - into the coin of the environmental realm." Dave Owen, Mapping, Modeling, and the Fragmentation of Environmental Law, 2013 UTAH L. REV. 219, 222. Owen suggests that "[t]he emergence of spatial analysis merits revisiting environmental law's traditional debates about integrative, holistic decisionmaking," although he refers to geographic and temporal rather than process-oriented fragmentation and does not address the implications of spatial analysis for enforcement. Id. at 223.

${ }^{243}$ Daniel C. Esty, Environmental Protection in the Information Age, 79 N.Y.U. L. Rev. 115, 156-57 (2004) (noting that new technologies may "provide on-the-ground monitoring of environmental conditions from anywhere, at any time, at increasingly low cost," revolutionizing responses to environmental problems"). See also Grabosky, supra 
previously available data and that can be more helpful in identifying environmental conditions, violations, and violators. The data can strengthen the deterrent impact of regulations and foster higher compliance levels if regulated entities recognize that ease of access to information may make it easier for enforcers to prove violations. ${ }^{244}$

Invoking the experience with the Toxics Release Inventory (TRI) program, the CWAP also touts the promise of transparency as a tool to improve compliance. ${ }^{245}$ EPA suggests that public pressure and greater regulated party self-awareness can both motivate better performance. For our purposes, the key point is that, in identifying strategies to improve compliance, EPA is looking well beyond ex post enforcement and considering a range of tools throughout the regulatory process. In doing so, it is by no means dismissing the value of traditional enforcement; it is simply calling for use of additional tools to address compliance challenges, a position we have taken in previous work ${ }^{246}$ and which academic literatures support. ${ }^{247}$ According to EPA, "[t]ransparency is not a replacement for regulatory enforcement, but can be an effective driver for improved performance and accountability."248 As others have noted, changes in information technology can affect phases of the regulatory process other than ex post enforcement. Better information, for example, can contribute to the adoption of more effective regulation, planning, and permitting, which in turn can affect the extent of compliance and the need for enforcement. ${ }^{249}$

The CWAP's third theme illustrates how considerations relating to hybrid governance and the dynamic nature of the regulatory environment can affect regulatory design choices, and that these aspects of regulatory design may affect key characteristics of effective regulation, including verifiability, the creation of appropriate compliance incentives, and regulatory

note 81, at 118 (noting the potential for digital technology to citizen enhance to "assist in labor-intensive investigation of non-compliance").

${ }^{244}$ Markowitz, supra note 242, at 228-29. Earlier iterations of improved data collection technologies have had that effect. See, e.g., Lesley K. McAllister, Enforcing Cap-and-Trade: A Tale of Two Programs, 2 SAN DIEGO J.

CLIMATE \& ENERGY L. 1, 4-8 (2010) (describing how continuous emissions monitoring equipment and automatic verification systems bolstered compliance levels under the CAA's acid rain program).

245 The TRI program was created by $\S 313$ of the Emergency Planning and Community Right-to-Know Act, Pub. L. No. 99-499, 100 Stat. 1729, 1741 (1986) (codified at 42 U.S.C. $\S 11023$ ). It requires facilities that manufacture, process, or use listed toxic chemicals in amounts that exceed threshold quantities to submit to EPA and state officials toxic chemical release forms. This information is meant to inform persons about toxic chemical releases, assist research and data gathering, and aid in the development of appropriate regulations. 42 U.S.C. § 11023(h). The TRI program may not be an ideal model for improving transparency and verifiability. See, e.g., M.B. Pell, Ryan McNeill \& Selam Genrakidan, Exclusive: U.S. system for flagging hazardous chemicals is widely flawed, REUTERS, July 8, 2013, http://mobile.reuters.com/article/environmentNews/idUSBRE9670K720130708 (describing investigation concluding that the TRI program is plagued by scant government oversight and by incomplete or inaccurate reporting by regulated entities, and charging that EPA and most states "make no effort to verify the [reported] data").

${ }^{246}$ See Markell, Deterrence-Based Enforcement, supra note _. Cf. Robert L. Glicksman \& Dietrich H. Earnhart, The Relative Efficacy of Coercive and Cooperative Enforcement Approaches to Water Pollution Control, in NEXT GENERATION COMPLIANCE, supra note 15, at _ (discussing deterrence-based, cooperative, and "responsive" regulatory approaches).

247 See, e.g., GOVERNANCE FOR THE ENVIRONMENT, supra note 3; NEXT GENERATION COMPLIANCE, supra note 15. ${ }^{248}$ CWAP, supra note 29, at 10.

249 See, e.g., Robert Thomason, More Data from Environmental Monitoring Now Supports Environmental Policy, Rules, 45 ENV'T REP. (BNA) 191 (Jan. 17, 2014) (discussing the impacts of scientific sensing equipment on programs to enhance water quality in the Chesapeake Bay). 
legitimacy. The range and relative attractiveness of regulatory design options, both for regulation as whole and for enforcement aspects of it, will shift over time as technology advances, government capacity evolves in other ways, and more is learned about what works and what doesn't in achieving desired environmental results. Regulatory design decisions should take full account of these contextual aspects of regulation.

\section{Enhancing Reinvention through Holistic Regulatory Evaluation}

While EPA's effort to improve enforcement and compliance efforts under the CWAP reflect many of the aspects of our multi-layered approach to regulatory design, the application of our framework to the initiative raises questions about several features of the CWAP. In this section, we provide a few examples of how a more complete accounting of all of the layers of our model for the design of regulatory enforcement and compliance programs might enrich EPA's analysis of each element of its CWAP. ${ }^{250}$

The first theme of EPA's CWAP centers on expanding the range of enforcement efforts to cover regulated sources previously ignored or deemphasized. EPA reasons that the discharges of small sources, particularly in the aggregate, have the potential to create significant adverse public health and environmental effects. Implicit in EPA's decision to sweep these sources into the agency's enforcement program is that doing so should increase the prospects of achieving desired levels of water quality. EPA may well prove to be correct, and as a normative matter we hope so.

Conceptually, we encourage systematic consideration of the role our five key components of effective enforcement and compliance might play as part of this new initiative. For example, are there strategies that would improve the regulated community's understanding of its regulatory obligations and how to meet them, as Colorado did with hazardous waste small quantity generators (our clarity component) ${ }^{251}$ Smaller facilities are less likely than larger counterparts to have access to sophisticated technical and legal advice. ${ }^{252}$ EPA has undertaken such outreach in other settings. ${ }^{253}$ Similarly, what are the implications of achievability for EPA's enforcement strategies for smaller facilities? Are there steps EPA can and should take in light of any achievability issues that are likely to materialize with respect to smaller facilities in particular? Verifiability is a third component that deserves careful consideration in determining how best to regulate a large universe of smaller facilities. Are there additional steps EPA should consider to facilitate effective self-monitoring? Or actions that could facilitate more effective government (EPA or state) monitoring and reporting? NGO capacity to participate in the verifiability component is worth attention as well.

\footnotetext{
250 These examples are intended to be illustrative of the value of using a conceptual framework of the sort we propose in this article in considering reforms to the enforcement and compliance promotion function, rather than to serve as a comprehensive assessment of options to enhance the CWAP.

${ }^{251}$ See supra notes 72-74 and accompanying text.

${ }^{252}$ Cf. Lisa Spagnolo, Rats in the Kaleidoscope: Rationality, Irrationality, and the Economics and Psychology of Opting in and Out of the CISG (Kaleidoscope Part II), 13 VindOBONA J. INT'L COMM. L. \& ARBITRATION 157, 159 (2009) ("As legal advice is a form of information cost, small-medium businesses face proportionately higher information costs, and are therefore more prone to imperfectly informed decision making and concurrent efficiency losses from less-suitable choices of law.").

253 EPA's website on Compliance Assistance, http://www.epa.gov/compliance/assistance/, provides access to many such outreach initiatives.
} 
Our fourth and fifth components (the mix of rewards and sanctions, and legitimacy) should influence when EPA brings cases against large and small facilities, and the relief the agency should seek. Perceptions of legitimacy may increase, for example, if EPA's enforcement program targets all suspected significant violators, regardless of size, particularly if small sources create adverse effects analogous to those resulting from discharges by larger facilities. On the other hand, coercive enforcement against small entities may seem unfair and overbearing to those sources if they lack adequate resources to comply, or if they lack the technical capacity to identify and quickly resolve problems. EPA policies account for disparities in the regulated community in terms of ability to pay; ${ }^{254}$ applying these fourth and fifth commitments, it would be appropriate for the agency to consider proactively whether other special accommodations are appropriate in deciding which suits to initiate and what relief to seek.

Our framework also suggests the value of deepening the analysis in connection with EPA's commitment in the second element of its plan to achieving a better integration of federal and state enforcement efforts. EPA's Plan does not address the role of citizen suits (an important aspect of hybrid governance in the enforcement and compliance promotion arena) in addressing the shortcomings it identified. The availability of citizen suits complicates the challenges of rationalizing or integrating federal and state compliance inducement efforts because such suits make it possible for three enforcers with different interests and capacities to take steps to address particular alleged violations. The challenges, and opportunities, are significant because of the significant number of actions citizen enforcers bring each year. ${ }^{255}$ Public enforcers have considerable discretionary authority over the fate of private enforcement; to use Professor Engstrom's phrase, the major federal pollution control statutes empower EPA and the states to serve as "gatekeepers" with respect to citizen suits. ${ }^{256}$ Nevertheless, there are significant limits on EPA's ability to influence citizen suit enforcers. A fully integrated analysis of the role of public enforcement by federal and state authorities should include an assessment of strategies that would "rationalize" the use of citizen suits so that, in combination, the three sets of enforcers have the best change of halting significant violations and inducing desired levels of compliance. $^{257}$ For example, weak gatekeeping is likely to create uncertainty for regulated entities (regarding the likelihood of suit, the types of relief to be sought, etc.). But strong gatekeeping that significantly disables private enforcement may detract from the legitimacy of the regulatory program if it is perceived as an effort by captured regulators to block public participation in efforts to halt violations with significant public health or environmental implications. While, therefore, we respectfully suggest that Professor Engstrom's prescriptions for rationalizing public and private enforcement lose some force because they largely exclude state enforcement, EPA's CWAP is similarly incomplete because it ignores the role of private enforcement. A comprehensive effort to design an enforcement and compliance regime that is

\footnotetext{
${ }^{254}$ Memorandum from Thomas L. Adams, Jr., to Assistant Administrators, Regional Administrators, Guidance on Determining a Violator's Ability to Pay a Civil Penalty (Dec. 16, 1986), available at http://www2.epa.gov/sites/production/files/documents/civilpenalty-violators.pdf.

${ }^{255}$ See supra note 48 and accompanying text.

${ }^{256}$ See supra notes 110, 211 and accompanying text.

${ }^{257}$ For previous inquiries into the relationship between public and private enforcement in the context of citizen suit enforcement, see, e.g., Jeffrey G. Miller, Theme and Variations in Statutory Preclusions against Successive Environmental Enforcement Actions by EPA and Citizens, Part One: Statutory Bars and in Citizen Suit Provisions, 28 HARV. EnVTL. L. REV. 401 (2004); Jeffrey G. Miller, Theme and Variations in Statutory Preclusions against Successive Environmental Enforcement Actions by EPA and Citizens, Part Two: Statutory Preclusions on EPA Enforcement, 29 HARV. ENVTL. L. REV. 1 (2005).
} 
up to the challenges of hybrid governance needs to take account, at a minimum, of the roles of all three enforcers, of how regulated entities are likely to react to the enforcement strategies of each, and of how each enforcer's effectiveness will be affected by the actions of the other two enforcers.

The CWAP's failure to consider the role of private enforcers in the CWA's hybrid enforcement program similarly may prevent the third aspect of EPA's CWAP, reliance on new information technology to enhance accountability and transparency, from completely fulfilling its potential. The dynamic nature of changes in information technology means that the economics, feasibility, and chances for success of enforcement will not remain static. Better monitoring and the information it generates, for example, may motivate regulated parties not to violate the law in the first place, thereby influencing the universe of cases that deserve formal enforcement. Better monitoring and information might heighten the willingness of private enforcers to pursue violators as information gathering costs decrease and the costs of success rise. These developments may spur citizen suits that would not otherwise have been brought, adding to the chances that regulatory policy will be set in the context of private litigation in ways which the government deems unwise. ${ }^{258}$ As Professor Engstrom has noted, however, when Congress created citizen suit provisions, it took into account and implicitly endorsed enforcement by private litigants that public enforcers might choose not to pursue, thereby "conferring democratic legitimacy, though at a higher level of generality," on such enforcement pursuits. ${ }^{259}$ Congress thus chose to forego a uniform enforcement regime in which expert federal agencies have the sole power to decide which enforcement actions will promote legislative goals, even though that might have been the best choice if its primary concern had been to avoid overdeterrence. Instead, Congress created a regime in which EPA shares its enforcement authority with states, largely for reasons rooted in a desire to promote federalism values. It also shares that authority with private enforcers, whose inclusion in the enforcement equation arguably promotes legitimacy in addition to reflecting Congress's intent to align enforcement capacity with levels of noncompliance warranting enforcement action in light of government resource constraints. These considerations are all relevant to policymakers as they consider the likely impacts of improved information technology on the preferred structure of enforcement and compliance programs.

\section{IV. $\quad$ Conclusion}

Enforcement is generally thought to be an indispensable feature of effective governance. The importance of using a holistic and systematic approach to consider reforms to agencies' enforcement and compliance functions is difficult to overstate because of the interconnectedness of the different components of an effective regulatory regime. Yet much agency effort to improve enforcement fails to account for the entirety of the administrative state's tools to conduct its work.

\footnotetext{
258 This concern has gotten traction with some Supreme Court justices. See, e.g., Friends of the Earth, Inc. v. Laidlaw Envtl. Serv. (TOC), Inc., 528 U.S. 167, 209 (2000) (Scalia, J. dissenting) (“A Clean Water Act plaintiff pursuing civil penalties acts as a self-appointed mini-EPA.”).

${ }^{259}$ Engstrom, supra note 3, at 638. Because citizen suits are expressly authorized by statutes such as the CWA, and the statutes specify who can sue and under what circumstances, private individuals and NGOs that qualify to bring such suits are not self-appointed at all.
} 
This article fills a gap in the law review literature by offering a comprehensive conceptual framework for considering how best to structure an enforcement and compliance promotion regime. The "test run" we gave to the framework by applying it to a case study of an ongoing EPA effort to reinvent its enforcement strategies under the Clean Water Act illustrated, at least to us, the value of efforts of this sort to use a wide lens in considering reforms to enforcement and compliance efforts. 